\title{
Theory Integration for Lifestyle Behavior Change in the Digital Age: An Adaptive Decision-Making Framework
}

Chao Zhang, PhD; Daniël Lakens, PhD; Wijnand A IJsselsteijn, PhD

Human-Technology Interaction Group, Department of Industrial Engineering \& Innovation Sciences, Eindhoven University of Technology, Eindhoven, Netherlands

Corresponding Author:

Chao Zhang, PhD

Human-Technology Interaction Group, Department of Industrial Engineering \& Innovation Sciences, Eindhoven University of Technology

PO Box 513

Eindhoven, $5600 \mathrm{MB}$

Netherlands

Phone: 31624749479

Email: chao.zhang87@gmail.com

\section{Related Article:}

This is a corrected version. See correction statement in: https://www.jmir.org/2021/4/e29629

\begin{abstract}
Despite the growing popularity of digital health interventions, limitations of traditional behavior change theories and a lack of theory integration hinder theory-driven behavior change applications. In this paper, we aim to review theories relevant to lifestyle behavior change from the broader psychology literature and then integrate these theories into a new theoretical framework called adaptive decision-making to address two specific problems. First, our framework represents lifestyle behaviors at two levels-one of individual daily decisions (action level) and one of larger behavioral episodes (reflection level) - to more closely match the temporal characteristics of lifestyle behaviors and their associated digital data. Second, the framework connects decision-making theories and learning theories to explain how behaviors and cognitive constructs dynamically influence each other, making it a suitable scaffold for building computational models. We map common digital intervention techniques onto the behavioral and cognitive processes in the framework and discuss possible contributions of the framework to both theory development and digital intervention design.
\end{abstract}

(J Med Internet Res 2021;23(4):e17127) doi: 10.2196/17127

\section{KEYWORDS}

behavior change; health behavior; digital health intervention; decision-making; learning; self-control; habits; theoretical framework

\section{Introduction}

\section{Background}

Digital intervention systems have been considered as promising tools to change people's unhealthy lifestyle behaviors, such as eating fast food, not exercising, or having suboptimal dental routines [1-4]. In realizing the potential of such systems, many researchers have advocated the role of behavior change theories, especially their translation to digital lifestyle interventions [3,5-8]. Ideally, behavior change theories and digital lifestyle interventions should inform each other. Good theories, when applied appropriately, are generally expected to increase the effectiveness of interventions. They can be used to identify behavioral determinants as intervention targets, translate general behavior change techniques (BCTs) to fine-tuned features in digital systems, and predict intervention outcomes. On the other hand, the vast amount of behavioral data collected by digital systems could potentially contribute to theory evaluation [9-11]. Compared with data from traditional behavioral experiments, digital behavioral data can have larger and more diverse samples, greater ecological validity, and higher temporal resolution.

Despite these expectations, the synergy between theory development and intervention practice is far from ideal [9]. The role of behavior change theories in digital interventions is not as prominent as hoped. Several surveys indicate that the application rate of theories in digital intervention trials and commercial eHealth apps ranges between $19 \%$ and $52 \%$ [6,12-19], and when theories are applied, only 3-5 classical theories dominate the applications [15,17,19-21]. Moreover, 
although some reviews and meta-analyses have suggested that applying theories has benefits [22,23], other reviews found no clear evidence [24-26] and questioned the value of applying theories in real-world applications [27]. Finally, as for theory development, data collected by digital systems are commonly used to evaluate the effectiveness of specific interventions but are rarely used to examine predictions derived from theoretical models [25].

One factor contributing to this theory-interventiongap is the lack of theory integration in the field of behavior change research [28], especially integrations that are tailored to digital lifestyle interventions. Even for a phenomenon as complex as behavior change, the large number of individual theories pertaining to behavior change ( 83 according to a systematic review [20]) clearly suggests that some integration and unification is probably beneficial for theory development in the field. The sheer number of behavior change theories can be overwhelming for intervention designers who want to grasp the literature and selectively apply theories to their designs. Perhaps the difficulty of orienting oneself with respect to the literature can explain why only a limited set of theories are applied [20]. Many basic theoretical ideas in psychology, despite being highly relevant, are underrepresented in applied research, such as decision-making, reinforcement learning, self-control, and habit formation.

The lack of impact of theories on interventions also raises the question whether the current knowledge about lifestyle behavior change is too limited to be fully useful. Two specific reasons have been proposed to explain why traditional behavior change theories are inadequate in the digital age [6]. First, many prominent traditional theories are static rather than dynamic, in the sense that they provide snapshot explanations of what factors determine behavior. Temporal aspects are not taken into consideration. Second, even when time is included in the theories, there is often a mismatch between traditional theories and digital interventions in terms of at what temporal scale behaviors are represented. These two limitations are evident in three of the most applied theories [15,17,19-21]. In the Theory of Planned Behavior (TPB) [29], neither temporal dynamics of the behavioral determinants in the model nor any mechanisms to account for the reciprocal influences of behavior on its determinants are specified. The influential Transtheoretical Model (TTM) includes the temporal aspect of behavior change stages [30]. However, although a healthy-eating app may intervene in its users' daily dietary choices, the TTM only describes the stages of behavior change in terms of months. If a theory represents behavior at a coarse temporal scale, processes at finer scales are overlooked and time-intensive digital interventions cannot be informed. Other theories, such as the Social Cognitive Theory (SCT) [31], consider more rapid interactions between behavior and behavior determinants (eg, self-efficacy); however, the dynamic interaction is theorized only at a very abstract conceptual level without explicitly modeling the role of time or how the interaction works [32]. Both criticisms also coincide with the recent advocates of paying more attention to temporal aspects in health psychology to improve theories and their translation into practice [32,33].

The two aforementioned points should not be considered as criticism of the original theories. Although these theories have been applied in the context of lifestyle behavior change and digital intervention, they were either not meant to explain lifestyle behaviors initially (eg, TPB) or developed at a time when technologies for continuously monitoring lifestyle behaviors were unavailable (eg, TTM or SCT). To advance theories, it is useful to consider some of the often-overlooked characteristics of lifestyle behaviors through the lens of modern digital technologies. Lifestyle behaviors, such as eating, exercising, or toothbrushing, are performed very frequently, as part of everyday habits and routines, and on each occasion, they are fast decisions that are not extensively deliberated. This type of decisions (eg, choosing what to eat for dinner) may be relatively inconsequential; however, they can form larger behavioral episodes (eg, following a diet), which may affect one's health significantly over time. This characteristic of hierarchical organization sets lifestyle behaviors apart from single-time health behaviors or decisions, such as cancer screening or vaccination. Moreover, unlike single-time decisions, as lifestyle behaviors are repeated frequently, learning and adaptation through repetitions plays a very significant role in lifestyle changes and interventions. This requires the inclusion of temporal dynamics in behavior change theories.

\section{Objectives}

On the basis of the aforementioned rationale, we propose a new integrative theoretical framework, called adaptive decision-making, which specifically focuses on lifestyle behaviors and incorporates temporal dynamics. In doing so, the new framework represents lifestyle behaviors at two temporal levels: a lower level (action level) that matches the daily individual decisions and the time-intensive interventions realized by digital systems and a higher level (reflection level) that matches the episodes of repeated decisions (Figure 1). In addition, both decision-making processes (how behaviors are determined or decisions are made) and learning processes (how earlier behaviors or decisions influence later ones through cognitive variables) at each level will be included in the framework. The goal is to incorporate both traditional and more recent theoretical ideas about behavior change in a single framework and reinterpret these ideas in light of a fine-grained temporal perspective. We hope this effort will facilitate a more integrated approach for developing more precise theories (eg, computational models) and intelligent intervention systems. 
Figure 1. A two-level representation of lifestyle behavior (change).

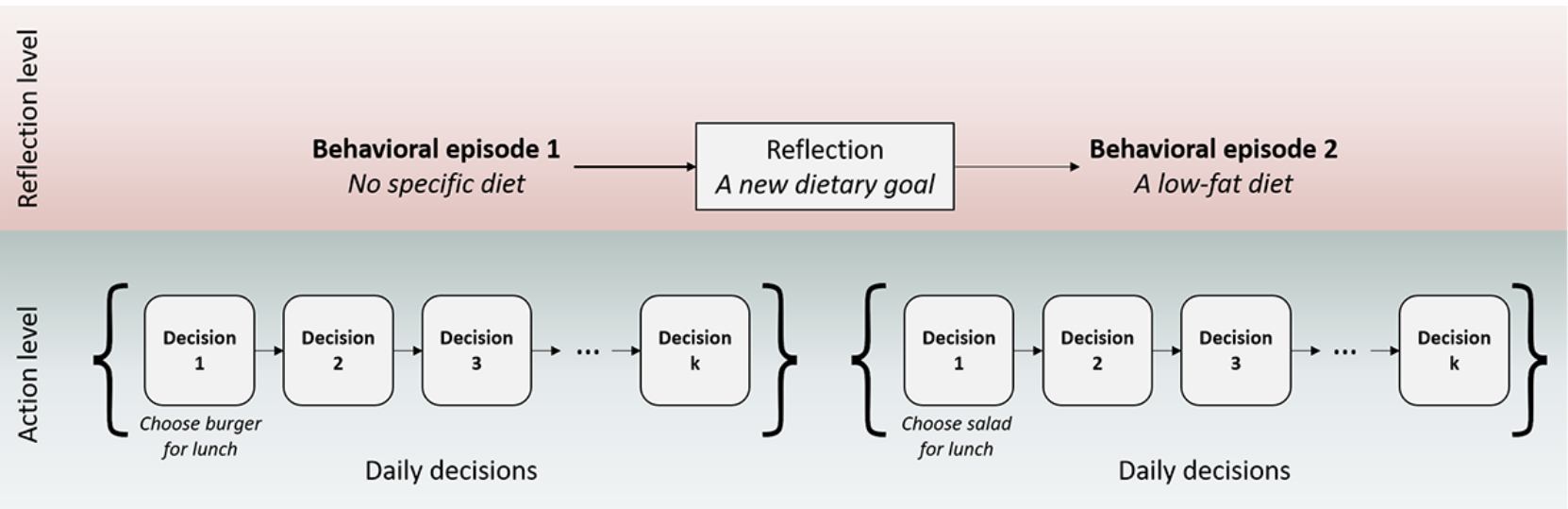

In the remainder of this paper, we first review important theoretical ideas relevant to lifestyle behavior changes from a broad psychology literature. To facilitate theory integration, individual theories are compared in terms of their temporal scales and their emphasis on learning or decision-making. Next, the adaptive decision-making framework is introduced by integrating the relevant but disparate theoretical ideas into a 2-level representation of lifestyle behavior changes presented earlier (Figure 1). Afterward, we relate the framework to intervention practice by mapping common BCTs used in digital systems to the behavioral processes in the framework. The paper concludes with a general discussion on the added value of the framework to behavior change theorists and digital intervention designers.

\section{Review of Individual Theories Relating to Lifestyle Behavior Change}

\section{Overview}

There are two distinct and complementary traditions for explaining human behavior-a learning tradition and a decision-making tradition [34]. The learning tradition, as its name suggests, focuses on the time course of learning a behavior - in particular, the interdependence among behavioral occasions in a sequence rather than the exact determinants of each occasion. In contrast, researchers in the decision-making tradition care more about what factors determine a behavior on specific occasions and what information is processed at such moments but much less on how repeated decisions are interrelated. As both learning and decision-making aspects are crucial for developing a dynamic framework, this review is organized based on the roots of theories in either tradition. After the review, we briefly discuss whether each theory focuses primarily on explaining individual daily decisions (action level) or episodic behavioral processes (reflection level).

\section{Theories in the Learning Tradition}

\section{Reinforcement Learning Theory}

Reinforcement learning, or learning by outcomes, is a fundamental form of learning discovered in the early years of modern psychology [35] and is still influential in today's behavioral and brain sciences [36] and artificial intelligence research [37]. Humans and other organisms are theorized to adapt their behaviors through their interactions with changing environments to survive and thrive. If a behavior results in goodness to an organism, the frequency of performing the same behavior increases; conversely, if a bad outcome follows, the behavior will be performed less often in the future. This is summarized as the law of effect [38].

Reinforcement theory becomes more complex when one also considers the law of exercise [38]. The aforementioned response-outcome learning, or goal-directed learning, is accompanied by stimulus-response learning, also known as a process of habit learning [36]. The distinction between goal-directed learning and habit learning has been demonstrated in instrumental learning experiments where animals or humans are trained to acquire reward-generating responses (eg, pressing a lever to receive food): when a response is overly trained, it persists to be triggered by the corresponding stimulus even when the reward becomes goal irrelevant (eg, when a rodent is satiated) [39]. The recent resurgence of interest in habit formation in social and health psychology also follows the theory of defining habits as mental associations between behaviors and environmental cues [40-42]. When a behavior becomes strongly habitual, goal-related determinants of behavior, such as attitude and intention, cease to influence behavior [43].

\section{Control Theory of Self-regulation}

The classical reinforcement learning theory focuses on the role of external immediate rewards in controlling behavior but neglects the role of distal behavioral outcomes that may be cognitively represented. Following criticism of this limitation [44], the control theory of self-regulation assumes that people can mentally represent distal outcomes of goals, and the regulation of behavior is generally toward reducing the discrepancies between the goals and people's current status $[45,46]$. When a behavior leads to a reduced discrepancy, the reduction itself becomes a reinforcer of the behavior, similar to external rewards. This discrepancy-reduction mechanism is analogous to feedback control systems in engineering, where discrepancies between perceived states and a reference value are constantly monitored to maintain homeostasis.

The control theory also hierarchically represents goals and self-regulation. A 9-level hierarchical control system was proposed by Carver and Scheier [45], in which a behavior output from a higher level serves as the goal reference to the next lower 
level. For lifestyle behaviors, it is sufficient to consider three levels: long-term goals (eg, improving health), short-term goals (eg, walking 10,000 steps a day), and actions (eg, taking a specific walk). Taking actions leads to the fulfillment of short-term goals, which in turn brings a person closer to the long-term objectives. Self-regulation operates most frequently at the action level (ie, making daily decisions); however, people's attention can be shifted to higher or lower levels. Downward shifting occurs when lower-level motor control, which is normally highly automated, becomes temporarily impeded during action executions (eg, when learning a new motor skill or when a dysfunctional action has to be inhibited [47]). Upward shifting can be understood as self-reflective moments when a person reconsiders the attainability of a higher-level goal, which is more difficult to predict (Psarra [48]).

\section{Social Cognitive Theory}

SCT, proposed by Albert Bandura, is one of the most cited and applied theories in behavior change research [20,21]. The theory encompasses three key concepts: social learning [49], self-efficacy [50], and proactive control [31]. First, based on research on children's learning behaviors [51], Social Learning Theory posits that behaviors or attitudes are acquired not only through direct reinforcement but also by observing the behaviors and their corresponding consequences to others [49]. For many health-related behaviors, long-term health consequences are often learned by observing other people's behavioral outcomes. Second, based on organizational decision-making research [52], it was found that subjective belief in one's ability to perform a behavior was closely related to actual performance. According to the control theory mentioned earlier, this self-efficacy belief can be understood as a cognitive mechanism that simulates a series of future actions (eg, dinner choices every day) in an extended episode of goal pursuit (eg, adherence to a diet). If the mentally simulated actions fail to bring sufficient progress, a person may decide to abandon the goal pursuit altogether. Third, Bandura [31] was among the earliest scholars to discuss a discrepancy-production process called proactive control, in which a person sets higher goals to further motivate behavior. Thus, it complements the discrepancy-reduction mechanism at the core of the control theory. The idea that goals are susceptible to changes also allows the possibility of adjusting an unattainable goal downward to reduce its discrepancy to the current status. Altogether, the three concepts contribute to extending reinforcement learning and control theory by incorporating flexibilities in complex human behaviors.

\section{Theories in the Decision-Making Tradition}

\section{Expected Utility Theory}

Across behavioral sciences (eg, psychology and economics), many mathematical models have been developed to describe how people make choices, given a fixed set of alternatives (options, eg, fries or salad) and attributes (eg, healthiness or tastiness). A fundamental theoretical idea behind many models is the expected utility theory. The theory assumes that people integrate multiple attributes of choice alternatives (their potential for satisfying different personal goals) into a unidimensional construct called expected utility and then choose the alternative with the highest utility [53]. Formally, the expected utility is computed as $E V=\sum_{j=1}^{J} \sum_{n=1}^{N_{j}} V\left(x_{j n}\right) \times P\left(x_{j n}\right)$, where $V\left(x_{j n}\right)$ is the subjective value function for the $n$th possible value of attribute $j$, and $P\left(x_{j n}\right)$ is the probabilistic belief that attribute $j$ takes that value $[54,55]$. The equation implies that the expected utility of one choice alternative increases when choosing the alternative is likely to produce certain outcomes (large $P\left(x_{j n}\right)$ ) and when the outcomes are highly valuable (large $\left.V\left(x_{j n}\right)\right)$. For example, whether people choose salad over fries depends on both their beliefs about their respective benefits for health and their valuations of good health. The theory does not imply that people always consciously follow the equation to compute utilities but rather reflects key neural mechanisms that underlie decision-making [56]. In reality, conscious and deliberative computations are more common for single-time important decisions (eg, comparing different health insurance policies) than for fast daily lifestyle decisions.

\section{Sequential Sampling Models}

Empirical data from choice experiments have repeatedly shown that people are less rational than those suggested by classical choice models [57]. People are prone to be influenced by information that is seemingly irrelevant, for example, the addition of an inferior choice option [58] or framing of losses versus gains [59]. To account for these anomalies, a sequential sampling approach has been developed to dynamically model the cognitive process of decision-making, such as the multialternative decision field theory [60] and the associative accumulation model [57]. The new models share the idea that preferences for different choice alternatives are accumulated over time (eg, a few seconds) and the choice that is made is the choice whose preference signal is first to exceed a decision threshold. At each time step, the preference signals of choice alternatives fluctuate according to a process of utility comparison based on one [57] or multiple attributes (as in drift diffusion models [61]). The stochastic property of sequential sampling models enables them to explain the sensitivity of choices to subtle changes in choice sets and to predict decision time [56]. Finally, sequential sampling models suggest a mechanism for habitual choices, where repeatedly choosing an alternative may shift its starting position of preference accumulation toward a decision threshold at the baseline ([60], Zhang et al, unpublished data, 2021).

\section{Reasoned Action Approach}

Influenced by the expected utility theory [62] but with a strong focus on application, the reasoned action approach [63] has produced some of the most applied theories in behavior change research, such as the TPB $[29,64]$ and the Health Belief Model [65]. From a decision-making perspective, this approach categorizes attributes in certain choice situations into a smaller set of behavioral determinants that are generalizable to a wide range of behaviors and measurable by self-report. For example, in the TPB, regardless of the specific alternatives and attributes considered, factors affecting choices are categorized into three determinants, namely attitude, social norm, and perceived behavioral control [64]. When a specific behavior is considered (eg, dinner choice), attitude toward a choice alternative is further 
determined by many attributes [29], such as taste, nutrition, and price, whereas social norms are influenced by the perceived social consequences of choosing an alternative (eg, presenting oneself to be environmentally friendly). Perceived behavioral control, similar to self-efficacy, measures one's confidence in maintaining certain choices in the future. TPB was explicitly considered by Prochaska and DiClemente [29] as a model for behavioral prediction rather than for explaining the processes underlying overt behaviors or decisions or how such processes can be influenced.

The reasoned action approach also makes a strong assumption on the intentionality of behavior [66]. For example, behavioral intention is a prerequisite for actual behavior in the TPB [64]. Thus, this approach considers behaviors as planned or intended, resulting from careful deliberations on the pros and cons of certain behaviors. Such a theoretical position is reasonable because the reasoned action approach was developed to mainly deal with single-time decisions or the planning of behavioral episodes, rather than small daily decisions. When applied to lifestyle behaviors, this approach relies on aggregated behavior representations over a substantive period [67].

\section{Dual-Processing Models}

A recurrent idea in psychology is that humans possess two distinct modes or systems for processing information and making decisions. Although different dual-system models use different terminologies [68], it is widely accepted that one system is fast, impulsive, and largely automatic, and the other system is slow, reflective, and deliberate [69].

The Reflective-Impulsive Model [70] is a representative of this approach, and it has been explicitly applied to health-related behaviors [71,72]. The reflective system hosts various higher-order mental operations that rely on controlled processes and symbolic representations, including deliberate judgments, planning for goal pursuit, and inhibition of prepotent responses. In contrast, the impulsive system operates fast on associative clusters in long-term memory that group stimuli, affective states, and behavioral responses together. At the moment of a specific decision, the success of self-control depends on the relative ability of the processes in the two systems to activate the corresponding behavioral schemas. Several boundary conditions have been proposed to moderate the relative strengths of the two systems [72]. For example, people are believed to behave more impulsively when their behaviors are highly habitual, when their cognitive loads are high, and when their moods are positive.

\section{Temporal Scales Used in the Aforementioned Theories}

Figure 2 summarizes the learning and decision-making theories based on the temporal scales of behavior representation. A similar distinction was made by Karoly [66], where theories at the action level were called online theories and theories at the reflection level were called offline theories.

In the learning tradition, the reinforcement learning theory clearly represents behavior at the action level, as the outcome of each specific action or decision is modeled to have concrete impacts on the frequency of repeating the same action in the future. Reinforcement learning experiments also involve repeated trials within a relatively short period (eg, a few hours). The control theory of self-regulation, because of its hierarchical structure, covers both behavioral processes at the reflection level and the action level. SCT and its processes of self-efficacy and proactive control apply mainly to behaviors at the reflection level. Although the two processes may have counterparts at a lower level, as in the control theory, Bandura's [31] focus was clearly on voluntary and deliberative human behaviors.

In the decision-making tradition, mathematical models as part of the expected utility theory and the sequential sampling approach can be equally applied to decisions at both temporal scales, as long as decisions with clearly defined choice sets are considered. As discussed earlier, theories in the reasoned action approach deal mainly with decisions at the reflection level because of its assumption of intentionality. In contrast, dual-process models are mainly intended to account for small daily decisions, for which both reflective and impulsive processes play a role. There is a difference between reflective used in dual-processing theories and what we mean by reflection level, which will become clear after theory integration. 
Figure 2. Categorization of reviewed theories based on their theoretical traditions and temporal scales (theories that apply to both temporal scales are underlined).
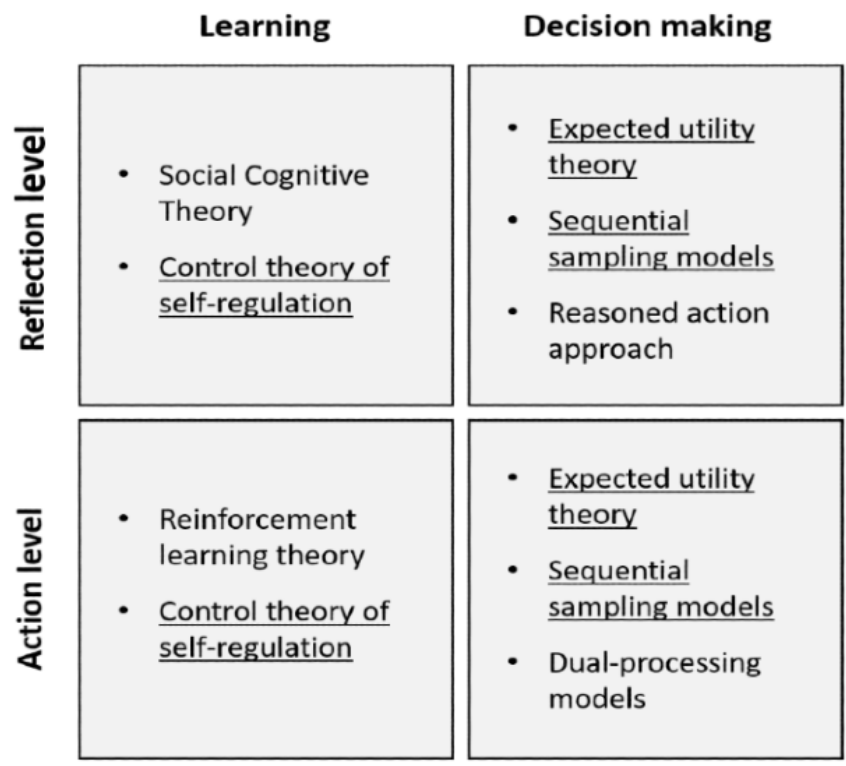

\section{Theory Integration: An Adaptive Decision-Making Framework}

\section{Overview}

To reiterate, our goal of theory integration is to develop a unified framework that identifies and connects all relevant decision-making and learning processes at both the action and reflection levels of lifestyle behavior change. Most processes in the framework came directly from the theories reviewed earlier, but efforts were made to unify different terminologies from different theories to form a coherent framework and to tailor the framework to lifestyle behaviors. Taking dietary behavior as a primary example, the framework should explain not only how daily meal choices are made and how each decision outcome influences future choices but also how the goal of adhering to a specific diet is made and how such goals are evaluated. The following sections introduce the adaptive decision-making framework in four parts: action-level decision-making, action-level learning, reflection-level decision-making, and reflection-level adaptation.

\section{Action-Level Decision-Making: Daily Meal Choices}

Daily lifestyle decisions, such as daily meal choices, can be modeled as a two-step process-option generation and option evaluation (Figure 3). The framework assumes that when choosing a meal, different meal options must be generated or recalled by a decision maker first, before evaluations of a few options can be made to inform a final choice $[73,74]$. The notion of option generation has not been examined in any of the decision-making theories reviewed, probably because most of the theories are based on laboratory choice experiments, where options are simply provided by the experimenters. For lifestyle behaviors in daily environments, how choice alternatives are generated is an important question. 
Figure 3. A two-step model of daily lifestyle decision making.

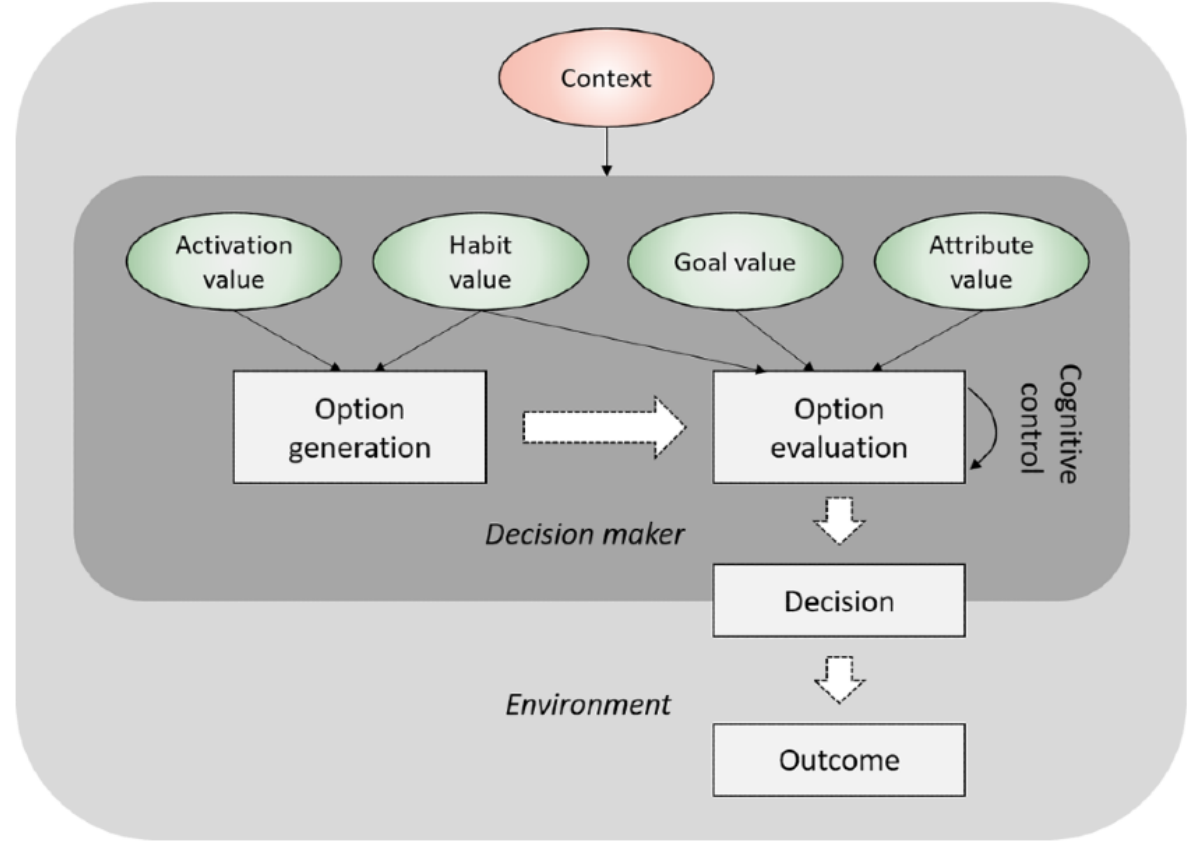

In general, behavioral options can be generated using three different methods. First, if an option is habitual, it will be activated when the associated cues are encountered, such as location and time (eg, lunch at the office) or a combination of contextual cues (eg, a busy Wednesday evening). Second, options may be remembered at the right moments because people intentionally try to maintain them in their prospective memory (ie, not to forget to do something in the future $[74,75]$ ). This usually happens when there is a salient goal guiding daily decisions, such as the goal of adhering to a low-carb diet. People may also intentionally associate important options with external cues so that encountering cues is likely to trigger the options [76]. Third, options can be triggered by direct external suggestions at the decision moments, for example, a coaching message from a mobile health app that recommends healthy foods [73]. Through these means, behavioral options that are sufficiently activated (eg, by passing an activation threshold) will be evaluated.

Option evaluation can be modeled as a process of comparing several options and then choosing the one with the highest goal-satisfying value. The exact computation of utilities can follow either classical expected utility models or more dynamic sequential sampling models. Here, it is sufficient to identify three main cognitive variables in the evaluation process. First, when multiple personal goals are relevant for a daily decision, these goals can be regarded as more or less important by a decision maker, thus entailing higher or lower goal values. For example, between the goals of living a healthy life and enjoying delicious food, a person who regards the former goal as more valuable would be more likely to choose food options for meals that satisfy their health goals.

Second, for each personal goal, a behavioral option has its perceived attribute value relating to that goal, which determines the total utility of the option. These attribute values are subjective beliefs held by people about the causal relationships or contingencies between choosing certain behavioral options and the realizations of personal goals. Although goal values are relatively more stable within-person, attribute values are more context-dependent and prone to changes through learning and experience. For example, the perceived taste of a particular meal option may depend on a person's momentary appetite, and it may change over time through repeated tasting of the food (ie, habituation [77]).

There is a particular challenge for making healthy decisions, as usually two distinct types of attributes are considered: an immediate hedonic aspect such as tastiness and a long-term consideration of health consequences. From a decision-making perspective, this challenge is essentially a problem of self-control [78]. According to the idea of temporal discounting in decision-making theories [79,80], as any reward from potential health improvements is delayed in time when compared with the immediate hedonic aspects, the value of the attribute healthiness is discounted before it is integrated in option evaluation $[81,82]$. Another reason why health aspects are often weighted less than hedonic aspects in actual decisions is that the former are more abstract concepts so they might be more difficult or take longer to be processed [83-86]. Finally, from a dual-processing perspective (eg, [54]), dietary self-control may sometimes succeed because people can voluntarily exert top-down cognitive control on the option evaluation process, especially if a momentary preference for a meal option conflicts strongly with a diet goal. It has been shown experimentally that cognitive control may either modulate the valuation process to be more in favor of healthiness rather than tastiness [87] or filter people's attention away from hedonic attributes in the early stage of option evaluation [88]. Effective top-down control depends on many contextual variables, such as motivation [89], mental fatigue [90], stress level [91], and daily affective states [92].

Third, habit values or habit strengths, which represent the history of choosing certain behavioral options, may influence the evaluation of options. As mentioned earlier, learning 
experiments have shown convincingly that even when two options are provided to decision makers, habitual options are more likely to be chosen than nonhabitual options [36,39]. In sequential sampling models, the influence of habits on the dynamic process of option evaluation can be understood as positively biasing the baseline preferences for habitual options ([60], Zhang et al, unpublished data, 2021). As an intuitive example, if someone often chose fast food in the past, fast food is by default more favorable than other options when no additional deliberations are made.

\section{Action-Level Learning and Adaptation: Developments of Eating Habits}

Action-level learning processes can be added to the framework by integrating the ideas of goal-directed learning and habit learning from the reinforcement learning theory to the two-step decision-making model proposed earlier (Figure 4). First, feedback from decision outcomes to perceived attribute values represents goal-directed learning. For example, when a new canteen is opened at a workplace, employees may have initial but very uncertain beliefs about the tastes and calories of different lunch options; however, after a few weeks of trying them out, they gradually form more accurate perceptions about the options. Computationally, the updates of perceived attribute values can be done through model-based and model-free reinforcement learning algorithms (eg, temporal difference learning [37]) or Bayesian belief update [93]. For health-related attributes, because concrete decision outcomes are infrequent except for extreme cases (eg, food poisoning), it is less clear how direct learning from experience works, if it is possible at all (Gershman and Daw [94]). People's beliefs about the health consequences of different foods are more susceptible to social learning and education.

Figure 4. Action-level learning processes added to the decision-making model.

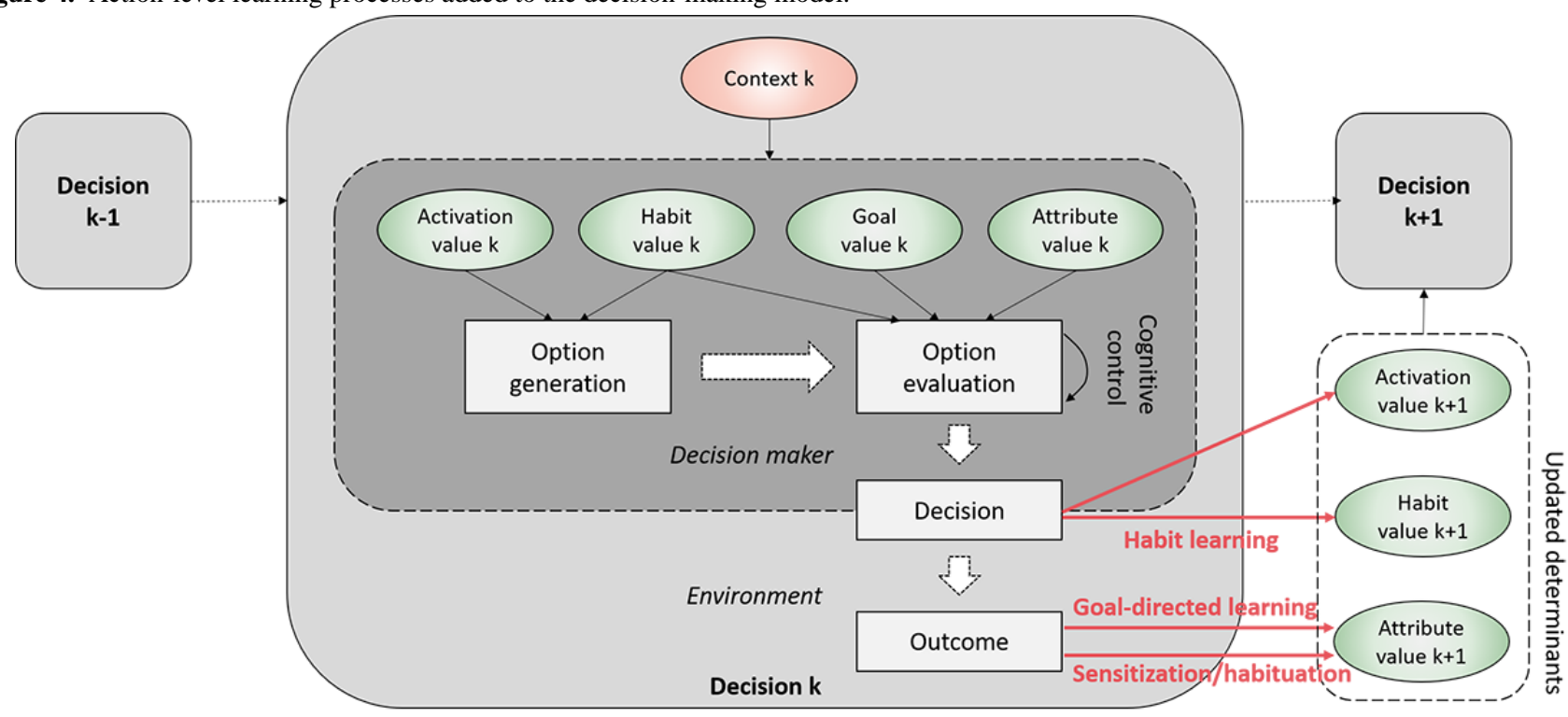

Second, there is direct feedback from decisions to habit values, as in the process of habit formation or habit learning. Although daily lunch decisions in a new canteen are driven primarily by goal-related attribute values, through repeated decisions, mental associations between frequently chosen food options and environmental cues (eg, the physical setting of the canteen or lunchtime) are gradually strengthened. These associations, as habit values, influence future decisions through both the option generation and option evaluation processes, as discussed earlier. The exact mechanism of habit learning is beyond the scope of this paper; however, it has been modeled in the literature $[48,72,95,96]$.

Third, there is also a direct link between decisions and the activation values of options, which has been discussed much less in the learning literature. When a decision is made and the corresponding behavior is executed, the behavior execution increases the activation level of the behavioral option in memory, although such an increase has been shown to be very small empirically [72]. As discussed earlier, the dynamics of activation values are primarily memory processes and are mostly affected by physical and social stimuli in the environment.
Fourth, with repeated daily actions and exposure to the sensory outcomes of the actions, people's neurological responses to the same sensory stimuli, depending on the parameters, may either intensify (sensitization) or fade away (habituation) [97]. This action-level adaptation is especially important for eating behavior, for which the exact same food becomes less palatable over time and accordingly its consumption will decrease [77]. This explains why the large variety in the modern food industry is considered a contributor to obesity [98]. In our framework, sensitization or habituation can be represented as an additional mechanism of sensory feedback from decision outcome to attribute value, in addition to the more cognitive process of goal-directed learning.

\section{Reflection-Level Decision-Making: Dietary Goal Setting}

Action-level decision-making and learning processes cover a substantial part of what people do in their daily lives. They depict lifestyle behaviors as repeated decisions without much purpose. However, people also have moments when they reflect on their health status, contemplate possible improvements, and make concrete plans. According to the control theory [45], these 
reflective processes require short-term goals that bridge people's abstract long-term goals (ie, what they pursue in their lives) and action-level daily decisions. Short-term goal setting can also be understood as a process of decision-making, albeit at the reflection level rather than the action level. The decisions made are commitments to goals that guide future daily decisions rather than overt behaviors that trigger motor programs.

Therefore, the two-step model of action-level decisions also applies to the setting of short-term goals. In selecting a dietary plan, for example, people first search for diet options that serve their long-term goals and then evaluate the options on relevant attributes, such as taste, ease of preparation, and expenses. At the reflection level, these attributes are often categorized into a few determinants, such as attitude, social norm, and perceived behavior control [29]. Nonetheless, goal setting differs from action-level decisions in some respects. First, because goal setting is less frequent than daily decisions, strong habits are unlikely to be formed to influence decision-making processes. Potential biases by habits are further reduced because people are more careful and take more time to generate goal options and evaluate them. Second, because people set goals for an extensive period of time in the future, they may form a more abstract mental construal [99], which is detached from direct sensory information and visceral attributes, such as effort and tastiness. Thus, the self-control problem for daily lifestyle decisions is less prevalent in goal setting. Third, self-efficacy plays an important role in goal setting [50]. People may carefully consider the feasibility of different diet goals by mentally simulating a series of daily dietary choices in the future.

\section{Motivating Functions of Short-Term Goals}

When short-term goals are generated, they can influence daily lifestyle decisions through both option generation and option evaluation (Figure 5). First, setting up a short-term goal can increase the activation values of desirable behavioral options through a process termed planning. Planning can be done through two mechanisms discussed earlier: an effortful prospective memory process (eg, rehearsing eating salads [75]) or an implementation intention process, that is, mentally associating a behavioral option with certain environmental cues (eg, eating an apple when watching television [76]). Second, compared with long-term goals, short-term goals are more concrete; therefore, complying with these goals brings immediate satisfaction [100]. Goal-compliance satisfaction functions as an additional attribute that competes with other hedonic attributes in the option evaluation.

Figure 5. A full representation of the adaptive decision-making framework (reflection-level processes and interactions between the 2 levels added to the previous decision-making model).

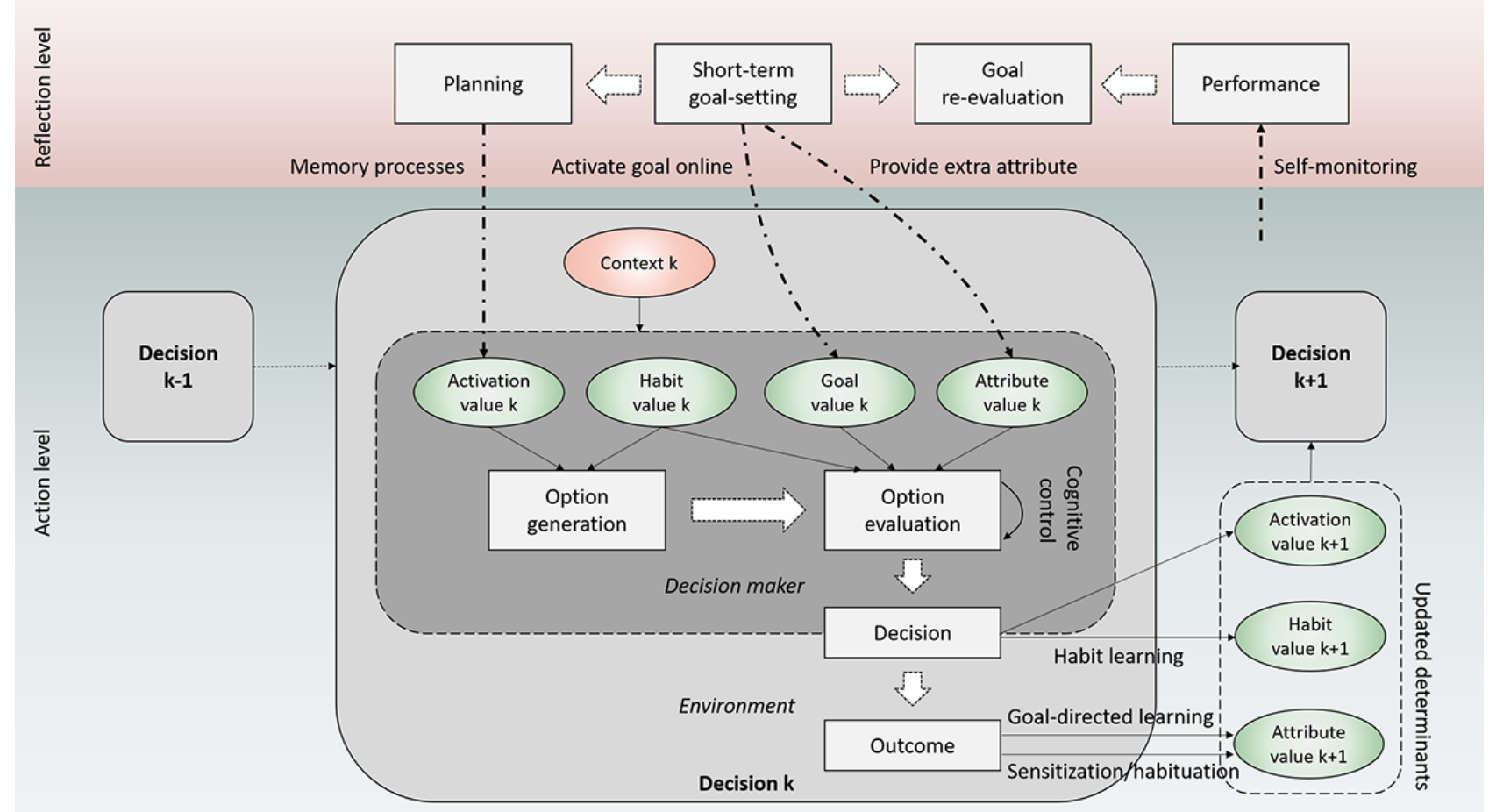

\section{Reflection-Level Learning and Adaptation: Self-monitoring and Re-evaluation of Dietary Goals}

Short-term goals must be re-evaluated in reflection moments periodically to change the goals that are too difficult, too easy, or no longer relevant. Such reflection-level adaptation processes are well described by the control theory [45] and SCT [31]. Goal re-evaluation first requires inputs from action-level processes through self-monitoring. Through repeated daily dietary choices, past choices and their outcomes are stored in episodic memory and are later retrieved and integrated into a mental representation of overall past performance (Figure 5). Next, discrepancy between a goal reference (eg, a dietary plan) and a performance representation is computed and used to inform the reflection-level adaptation. Depending on the size of discrepancies and other contextual factors, people may motivate themselves further to make healthy daily dietary choices to reduce the goal performance discrepancies. However, 
when discrepancies are deemed too large, people may instead lower their goal standards (eg, be less strict on calorie intake) or abandon their goals altogether (eg, give up a diet). Instead, when performance matches or even exceeds current goal standards, they may proactively adjust their goal standards upward to further improve their health [31].

\section{Mapping Digital Intervention Techniques to the Framework}

We define digital intervention techniques as BCTs or behavior change methods that target lifestyle behaviors and are implemented in digital systems (eg, web, mobile, or wearable systems). BCTs, in turn, are generally defined as the active ingredients of interventions that can influence behaviors in desirable ways [34,101,102]. Mapping BCTs to theoretical constructs is an important exercise when trying to evaluate and enhance the effectiveness of the techniques; such mappings have been carried out previously [102,103]. Focusing on their implementations in digital intervention systems, our mapping exercise is the first to connect BCTs to theoretical constructs in a single unified framework. Specifically, we categorize and interpret digital BCTs according to targeted behavioral processes and cognitive variables in the framework. The strengths and limitations of some techniques are discussed based on the implications of the framework.

\section{Digital Intervention Techniques Targeting Action-Level Decision-Making}

As digital systems are prevalent in people's daily lives, they are well positioned to influence people's daily lifestyle decisions at the time of the decision. The ability to target action-level decisions is considered by many as a promising direction for digital lifestyle interventions, as reflected in research on ecological momentary interventions [1] and just-in-time adaptive interventions (JITAIs) [104-108]. According to our framework, there are many different ways in which digital intervention systems can influence online decision-making processes, depending on whether the techniques target option generation or option evaluation and which cognitive variables are targeted; four main categories can be distinguished.

\section{Option-Based Techniques}

Option-based techniques make certain desirable behavioral options salient but leave the evaluation of options to users themselves. When a desirable behavior is obvious but may not be constantly salient to users, digital systems can simply prompt users to actively make decisions to engage in that behavior, for example, to take breaks when overly sedentary behaviors are detected by the system $[109,110]$. Otherwise, it might be possible to provide users with new options that are better than those known by users themselves [73]. Finding such attractive options relies on a system's sensor network and smart algorithms, which potentially make it more knowledgeable than its users in a given behavioral domain or context. For example, a smart system was developed to recommend new commuting routes to users in situ to increase physical activities, based on automatic detection of users' habitual routes and Google Maps data [111].

\section{Attribute-Based Techniques}

Attribute-based techniques aim to change users' beliefs about the attribute values of options by providing health-related knowledge or facts. They are referred to as providing information about behavior-health links or providing information about consequences in the taxonomy of BCTs [101]. Given the common assumption that humans are rational decision makers, providing information about attribute values is a logical approach to behavior change and has been used extensively in traditional health education campaigns. However, attribute-based techniques alone do not guarantee successful behavior change, as attribute value is only one of many factors that influence decision-making. It is also questionable whether digital systems are better tools for providing such information when compared with human experts (eg, lifestyle coaches). Nonetheless, information about attribute values can be provided to justify the recommendations of behavioral options whenever appropriate in digital systems (eg, calorie information for different meal choices).

\section{Goal-Based Techniques}

As goal values modulate attribute values in option evaluation, activating health-related goals in the decision moments provides yet another type of intervention technique. When implemented in digital systems, they link the suggestions of concrete behavioral options with the reminder of associated short-term or long-term goals. For example, when a mobile app prompts a user to take a lunch walk, the user's goal of walking 10,000 steps a day (and the achieved steps) can be presented along with the option of taking a lunch walk.

\section{Structure-Based Techniques}

Structure-based techniques differ from previous types because they neither change the availability of options nor alter users' existing beliefs about attribute values. As they require less processing effort and are less susceptible to reactance from users than other techniques, structure-based techniques have attracted significant research interest [112,113], usually under the name of nudging or choice architecture [114,115]. For example, people can become more likely to choose the desirable options when they are presented as default options [116] or an additional option is introduced to change their perceptions of choice sets (context effects [57]). Lee et al [117] adopted the default technique to promote healthy snacking in an online environment by making healthier options the default choices. Zhang et al [118] built on a context effect called the compromise effect to promote physical exercise at work using a mobile app. Intensive exercise options were added to make moderate exercise options appear more achievable and thus more attractive [118].

A challenge for all JITAIs is that most lifestyle behaviors are physical rather than digital in nature. When making decisions about snacking, exercising, or toothbrushing, people do not naturally come to digital applications. In contrast, in e-commerce, for example, people are accustomed to shopping online; therefore, e-commerce sites such as Amazon never miss the opportunity to influence consumers in their decision moments. To influence lifestyle decisions at critical moments, interfaces between the information in digital systems and 
people's spontaneous behaviors in the physical world need to be created. Current approaches include predicting users' spontaneous decision-making moments using sensor networks (eg, predicting about-to-eat moments [119]) and initiating decisions when interventions are predicted by the system to be most valuable (eg, predicting stressful moments [120]). This challenge will continue to stimulate new intelligent digital solutions and at the same time debates on the associated ethical implications [121].

\section{Digital Intervention Techniques Targeting Action-Level Learning}

Digital intervention techniques targeting action-level learning processes operate in between rather than at decision moments. The goal is to support either goal-directed learning or the formation of healthy habits. If these techniques are effective, the cognitive variables that influence decision-making will be in a health-promoting state, so that users are expected to maintain the learned healthy behaviors without continuous intervention by digital systems.

A main challenge for lifestyle behavior change is learning the causal relationships between one's behaviors and health consequences, as these consequences are usually delayed. As discussed, researchers have speculated on the role of episodic memory in tracking internal and external events to support this type of learning [94]. In this regard, the self-tracking function of many digital systems can support learning by externalizing the user's memory systems [98]. Behavioral and contextual data can be objectively recorded and reviewed later by users when consequential health events occur. As self-tracking studies mostly focus on the effectiveness of the technology as a whole, evidence regarding its specific role in supporting goal-directed learning is lacking [122]. Some interview data indicated that users of self-tracking systems believed that they acquired knowledge about behavior-health links through self-tracking technology [123,124].

Instead of directly supporting the learning of health consequences, another popular approach is to provide extra rewards that may reinforce desirable behaviors. In the so-called gamification systems, the most common extra rewards are virtual rewards, such as points, badges, or rankings in leaderboards [125-127]. These virtual rewards are expected to steer users to healthy behavioral options by competing with the inherent hedonic values of many unhealthy behaviors.

Despite its popularity, the effectiveness of virtual rewards in their simplest forms is questionable, as empirical studies found no positive effects in several health domains, such as physical activity [128] and sexual protection behavior [129]. Moreover, users in one study perceived such virtual rewards implemented in an exercise-promoting app as not motivating or even unnecessary [130]. Our framework implies that the problem with virtual rewards is not in the learning of the contingencies between behavioral responses and rewards but in the corresponding goal values of these rewards: the goal values of virtual rewards are often low, when compared with other hedonic attributes, such as tastiness and reduced effort. Future research on gamification should focus on making virtual rewards more goal relevant and meaningful [131], for example, by embedding them as a game mechanic that users care about [132], using tangible rather than intangible rewards [133,134], or making the rewards socially meaningful $[135,136]$.

Another technique in this category is habit formation support, usually by reminding users about a new and desirable behavioral option. This is especially valuable at the beginning of habit formation when new options are not always remembered by users themselves. Unlike the technique of suggesting options at decision moments, reminders that support habit formation are sent offline and according to time-based schedule (eg, once every morning). They do not persuade users to act immediately but to increase the activation values of certain options so that they are more likely to be generated when decision moments arrive. Reminders have been widely used and have been shown to be effective in domains where forgetting is the main obstacle for behavior change [137,138]. More research is warranted to understand its value in changing more complex lifestyle behaviors when the activation value is one of several cognitive variables.

\section{Digital Intervention Techniques Targeting Reflection-Level Decision-Making}

Setting up a short-term goal as a reflection-level decision-making process is often the starting point of self-directed behavior change [139]. Without external interventions, goal setting can be triggered under specific conditions, for example, when someone has learned new health-related knowledge (eg, become aware of the risk of smoking) or has experienced a sudden change in their health status (eg, being diagnosed with diabetes). Thus, a straightforward intervention technique is to proactively prompt users to set up new goals to improve their lifestyles. In many digital systems, following a goal-setting prompt, a user can choose a goal and then record it in the system, which allows the system to remind the user of the goal when needed.

As goal setting is a decision-making process, most techniques discussed in the section on targeting action-level decision-making also apply to goal setting, including option-, attribute-, and structure-based techniques. As a particularly promising direction, digital systems may use their data-gathering power and artificial intelligence to recommend novel and attractive options for short-term goals [73]. To address the subtlety and complexity of goal setting in the health domain, the systems need to personalize options based on users' abilities [140] and based on their unique life experiences and personal context [141-144]. In the future, the difficult task of setting up challenging, motivating, yet realistic goals may indeed be transferred from people to intelligent intervention systems, at least in part.

After the goal-setting step, digital systems can go further to support the planning phase that connects short-term goals to daily decisions in the future. A simple technique is to prompt users to make concrete plans in the system, for example, by adding activities to a calendar. Data provided by users allow digital systems to check user adherence and send reminders when necessary. In addition to this time-based planning technique, digital systems may encourage users to use the event-based planning technique of implementation intention 
[76]. Implementation intention has been shown to be effective in the health domain [145,146], and it has also been implemented in digital interventions where no human instructions are required [147,148]. A recent system even uses sensor data to automatically generate if-then rules adapted to the living contexts of individual users [149].

\section{Digital Intervention Techniques Targeting Reflection-Level Adaptation}

At the level of reflection-based adaptation, providing behavioral feedback to users to support self-monitoring is the most commonly used BCT in digital systems [19,150-153]. Technically, with the development of increasingly powerful sensors, digital systems are able to track lifestyle behaviors and related variables more accurately and in greater detail than people's own memories. Moreover, these systems can transform the rich raw data into numerical or visual information (eg, weekly summary of step count) to facilitate better comparison with short-term goal references [122].

Although self-monitoring as a general BCT has been identified as effective [154], the evaluation of this technique in digital systems has yielded mixed results $[153,155]$. The evaluation is also impeded by the lack of high-quality studies and a lack of focus on self-monitoring per se [122]. It is evident that the abundance of self-tracking devices has not solved the problem of lifestyle behavior changes. From an evolutionary perspective, as people's natural self-monitoring function has existed long before the existence of digital systems and quantitative data, it is not self-evident that technology-enhanced information would lead to better functioning. A recent study indicates that some self-tracking users may have an exaggerated focus on numeric feedback as the replacement of bodily experience as feedback, potentially leading to negative consequences such as rumination [156]. The bottom line is that even if technology-enhanced self-monitoring is beneficial to some extent, our framework implies that it is only one step in reflection-level adaptation. Future research should investigate how digital systems can also support reflective processes that immediately follow self-monitoring, including the comparison between goal references and monitored performance and the adjustments of goals and behaviors.

\section{Discussion}

\section{Overview}

Understanding and changing lifestyle behaviors in the digital age require a theoretical perspective that combines decision-making and learning and a representation of behavior at the level of both daily decisions and episodic reflections. These two requirements have guided our review of individual theories and their integration, and the outcome is temporally fine-grained, dynamic, and process-oriented theoretical framework of lifestyle behavior change. Through a mapping exercise, we also linked common digital intervention techniques to behavioral processes and cognitive constructs in the framework.

\section{Theoretical Contributions and Comparisons With Previous Integration Works}

The primary objective of developing an adaptive decision-making framework is to address the mismatch between theory and digital intervention in terms of temporal granularity [6]. This was done by considering lifestyle behaviors at two different timescales, one representing the individual daily decisions or actions and one grouping the repeated daily decisions into a larger episode and incorporating self-regulatory processes. This 2-level representation adds value over previous integration attempts that were based on the stage model of change [30], such as the computerized behavior intervention (COMBI) model [157,158] and the i-Change Model [159]. Although the COMBI and i-Change Model postulate a more general process of behavior change (eg, through contemplation, preparation, action, and maintenance), our framework allows one to zoom to a finer level of granularity to explain how repeated daily actions, with the help of reflection-level regulatory processes, lead to maintenance. With time-intensive behavioral monitoring becoming more accessible, our framework compliments earlier work by motivating future intelligent systems that update users' behavioral and cognitive states after every daily lifestyle decision (eg, computing self-efficacy [160]). In our own work, we proposed a system that computes users' habit strengths of toothbrushing based on sensor-measured behaviors [161].

There are previous frameworks that are more similar to our adaptive decision-making framework when it comes to behavior representation. Both PRIME (Plan, Responses, Impulses, Motives, and Evaluations) theory [162] and Temporal Self-Regulation Theory [163] model behavior change as a continuous process rather than a series of discrete stages. However, our framework explicitly distinguishes between the two distinct levels of lifestyle behaviors and the different timescales involved. Note that similar to many other dichotomies used in psychology (eg, impulsive vs reflective, unconscious vs conscious), although our 2-level dichotomy is a simplification of a potential continuum of processes, it is still useful for developing new theories, empirical research, and applications. The conceptual distinction is important because it enables our framework to represent lifestyle behaviors at the same temporal granularity with time-intensive behavioral data while incorporating cognitive processes that are detached from daily decisions (eg, goal setting or planning).

A second limitation in the current literature is the lack of dynamic processes in traditional behavior change theories [6]. By integrating theories from both learning and decision-making tradition, our framework depicts a dynamic bidirectional relationship between behaviors and cognitive variables that influence behaviors. The framework complements previous frameworks that focused exclusively on learning processes, such as the framework of evolutionary learning processes [97] and Action Change Theory [164]. More broadly, we believe that the need to capture the complexities of lifestyle behaviors for designing better digital interventions provides a strong and timely motivation to integrate decision-making and learning theories in basic psychological research [165]. 
Furthermore, this study may stimulate some rethinking about the popular dual-processing models, in which health behaviors are assumed to be driven by two distinct forces, one reflective and one impulsive [72]. In our view, such dichotomous categorization of diverse processes and constructs might be too coarse for a full understanding of the dynamic lifestyle behavior change process. The adaptive decision-making framework suggests several dualities. First, there is a contrast between long-term health benefits and immediate hedonic rewards in option evaluation, where effortful cognitive control is required to battle impulses. Second, goal-directed evaluation based on attributes (both long-term and short-term) competes with the influences of habits. This has been discussed extensively in the learning literature as a dual action control by goals and habits [166]. Third, the faster processes at the action level can certainly be contrasted with the more deliberative processes at the reflection level, which also operate on a much slower timescale. Note that this distinction between action and reflection levels certainly reminisces the classical distinction between motivation and volition [167] and the related Rubicon model of action phases [168].

Finally, the process-oriented nature of our framework makes it an ideal scaffold for developing new dynamic computational models envisioned by many researchers $[6,104,169,170]$. The processes and mechanisms in the framework are described at a level of specificity that allows their transformation into computational models by introducing additional assumptions and formal algorithms. For example, key cognitive variables are defined for option evaluation, but the exact computational process of how these variables are integrated to produce decisions is left open to different modeling possibilities [44,171]. Similarly, although the framework acknowledges the joint influence of habit and goal-directed control, the exact arbitration between the two is subjected to different computational accounts [96,172,173].

\section{Added Value to the Synergy Between Theory and Digital Intervention}

The adaptive decision-making framework was developed with the aim of narrowing the gap between behavior change theories and digital intervention applications. As a first step, the framework provides a summary of the main theoretical ideas in psychology relevant to applied behavior change research. As such, it can be used as a reference if practitioners want to read more about specific theories and computational models. The integration of both traditional and more cutting-edge theories in the framework should help practitioners to see familiar theories (eg, self-efficacy and goal setting) in a new light and hopefully motivate them to experiment with new ideas (eg, habit formation or sequential sampling models of decision-making). What is especially promising is the prospect of designing intelligent close-loop intervention systems based on computational models informed by our framework. In the current best practice, behavior change determinants and corresponding BCTs are identified and then carefully translated into functions in digital applications; however, their effects on behavior are simply speculated (open loop). By relying on computational models, intelligent systems can monitor behaviors that are targeted and use behavioral data to update the cognitive variables of users to deliver JITAIs for each individual user [107,174]. Examples of such close-loop systems can be found in recent works by other researchers [160] and ourselves [161].

Moreover, our framework's emphasis on behavioral processes and their corresponding digital intervention techniques should contribute to the identification, implementation, and evaluation of intervention techniques. First, similar to an intervention mapping approach [102], our framework makes a clear distinction between people's behavioral processes and the techniques that may influence these processes, which is not always made in other coding taxonomies. For example, habit formation has been considered a BCT [101]; however, it is essentially a behavioral process that also operates without interventions and is driven by multiple lower-level processes. It is more informative and actionable for system designers if they are informed about the specific processes underlying habit formation and how they can be changed rather than simply implementing a technique called habit formation. Second, by mapping digital intervention techniques to behavioral processes in our framework, it should become clear that a technically well-defined function often targets multiple distinct behavior processes. For example, self-tracking may increase users' knowledge about behavior-health links but may also support self-monitoring [122]. We argue that evaluation research (eg, review and meta-analysis) should focus more on the effects that specific intervention techniques have on individual processes rather than the effectiveness of broadly defined categories of technologies (eg, feedback system [155]), to gain a better understanding of how and why certain intervention techniques work. Third, when combining multiple intervention techniques within a single digital system, our framework can inform designers about whether the techniques target complimentary processes and constructs or the same process and construct. In the latter case, the combination of techniques as a package may not necessarily be more effective than its components, and more careful analysis is needed. For example, as implementation intention and just-in-time reminder both increase the activation values of desirable options, it is questionable whether combining them would yield better results (Luszczynska et al [147]).

The adaptive decision-making framework may also help to encourage the use of digital lifestyle intervention systems to advance basic human behavior sciences. We have emphasized in this paper the unique opportunities of bringing psychology laboratories to the real world [175,176] and exploiting the time-intensive and ecologically valid behavior data generated by digital systems [9-11]. The integration of fundamental psychological processes in the framework, such as reinforcement learning and sequential sampling models of decision-making, can increase the awareness of scientists in these fields to the practical value of their research and the great potential value of using digital systems in the field as data collection tools for fundamental social science research. We also hope that by summarizing and structuring the theoretical landscape for digital system designers, they can find their potential collaborations with behavioral scientists more efficiently. Finally, the clear mapping between intervention techniques and the processes and constructs in the framework makes it easier to search for the required data and manipulations to be used for theory testing. 


\section{Scope and Limitation of the Framework}

Given the ambitious goal of the framework to incorporate a wide range of theoretical traditions and to connect to the full gamut of digital intervention techniques, it is important to discuss the scope and limitations of our framework. First, the adaptive decision-making framework is not a new theory in itself or a model to be directly tested or falsified in a strong empirical sense. It is a framework that integrates existing theoretical ideas into a novel representation of lifestyle behaviors. In other words, it identifies relevant explananda in the course of lifestyle behavior change and provides explanations based on the most recent theoretical advances available. The usefulness of the framework should be judged by whether it succeeds in informing new computational models and intelligent intervention systems in the future, and predictions derived from the framework and its associated computational models should be rigorously tested using empirical data.

Second, proposing an integrated framework is not meant to discourage the use of individual theories in digital interventions. The adaptive decision-making framework is a framework of basic behavioral and cognitive processes in lifestyle behavior changes that are generalizable to a wide range of behavioral domains. However, there is also large heterogeneity across different behavioral domains and target populations, in terms of which processes in the framework are more critical and which variables or parameters are more changeable. For this reason, specialized theories are always needed, even if future theoretical advances might allow a single unified theory of basic psychological mechanisms. Therefore, it makes perfect sense for digital intervention systems to focus on one or a few processes or to target only a small set of variables for change based on domain-specific theories. The theoretical scope of the framework itself is focused on explaining individual lifestyle behaviors. It does not address interactions between individuals or larger socioeconomic processes.

Third, the adaptive decision-making framework is a theoretical framework of behavior change but not a framework of digital intervention systems. We have discussed the educational and heuristic value of the framework for digital intervention designers to help them understand and apply theories. It can potentially also motivate and facilitate the development of intelligent intervention systems that model user behaviors and cognitive states $[161,174]$. However, the framework should not be considered as a cookbook in the sense of prescribing specific design choices or requirements in specific interventions.

\section{Conclusions}

We developed an adaptive decision-making framework in the hope that it will benefit behavior change theorists and digital system designers and, most importantly, facilitate better communication between the two communities. A stronger synergy will potentially help bring us closer to a future where digital systems live up to their potential to promote healthy lifestyles at scale. In the meantime, a wider adoption of more effective and theory-driven digital interventions will offer ample opportunities for building and testing new theories of human behavior.

\section{Conflicts of Interest}

None declared.

\section{References}

1. Heron KE, Smyth JM. Ecological momentary interventions: incorporating mobile technology into psychosocial and health behaviour treatments. Br J Health Psychol 2010 Feb;15(Pt 1):1-39 [FREE Full text] [doi: 10.1348/135910709X466063] [Medline: 19646331]

2. IJsselsteijn WI, De Kort Y, Midden C, Eggen B, van den Hoven E. Persuasive technology for human well-being: setting the scene. In: Persuasive Technology. Berlin: Springer; 2006:18-19.

3. Kaplan RM, Stone AA. Bringing the laboratory and clinic to the community: mobile technologies for health promotion and disease prevention. Annu Rev Psychol 2013 Jan 03;64(1):471-498. [doi: 10.1146/annurev-psych-113011-143736] [Medline: 22994919]

4. Klasnja P, Pratt W. Healthcare in the pocket: mapping the space of mobile-phone health interventions. J Biomed Inform 2012 Feb;45(1):184-198 [FREE Full text] [doi: 10.1016/j.jbi.2011.08.017] [Medline: 21925288]

5. Michie S, West R. Behaviour change theory and evidence: a presentation to Government. Health Psychol Rev 2013 Mar;7(1):1-22. [doi: 10.1080/17437199.2011.649445]

6. Riley WT, Rivera DE, Atienza AA, Nilsen W, Allison SM, Mermelstein R. Health behavior models in the age of mobile interventions: are our theories up to the task? Transl Behav Med 2011 Mar;1(1):53-71 [FREE Full text] [doi: 10.1007/s13142-011-0021-7] [Medline: 21796270]

7. Patel MS, Asch DA, Volpp KG. Wearable devices as facilitators, not drivers, of health behavior change. J Am Med Assoc 2015 Feb 03;313(5):459-460. [doi: 10.1001/jama.2014.14781] [Medline: 25569175]

8. Walsh JC, Groarke JM. Integrating behavioral science with mobile (mHealth) technology to optimize health behavior change interventions. Eur Psychol 2019 Jan;24(1):38-48. [doi: 10.1027/1016-9040/a000351]

9. Dunton GF, Atienza AA. The need for time-intensive information in healthful eating and physical activity research: a timely topic. J Am Diet Assoc 2009 Jan;109(1):30-35. [doi: 10.1016/j.jada.2008.10.019] [Medline: 19103320]

10. Moller AC, Merchant G, Conroy DE, West R, Hekler E, Kugler KC, et al. Applying and advancing behavior change theories and techniques in the context of a digital health revolution: proposals for more effectively realizing untapped potential. $\mathbf{J}$ Behav Med 2017 Feb;40(1):85-98 [FREE Full text] [doi: 10.1007/s10865-016-9818-7] [Medline: 28058516] 
11. Rothman AJ. "Is there nothing more practical than a good theory?": why innovations and advances in health behavior change will arise if interventions are used to test and refine theory. Int J Behav Nutr Phys Act 2004 Jul 27;1(1):11 [FREE Full text] [doi: 10.1186/1479-5868-1-11] [Medline: 15279674$]$

12. Prestwich A, Webb TL, Conner M. Using theory to develop and test interventions to promote changes in health behaviour: evidence, issues, and recommendations. Curr Opin Psychol 2015 Oct;5:1-5. [doi: 10.1016/j.copsyc.2015.02.011]

13. Al-Durra M, Torio M, Cafazzo JA. The use of behavior change theory in internet-based asthma self-management interventions: a systematic review. J Med Internet Res 2015 Apr 02;17(4):e89 [FREE Full text] [doi: 10.2196/jmir.4110] [Medline: 25835564]

14. Conroy DE, Yang C, Maher JP. Behavior change techniques in top-ranked mobile apps for physical activity. Am J Prev Med 2014 Jun;46(6):649-652. [doi: 10.1016/j.amepre.2014.01.010] [Medline: 24842742]

15. Dahlke DV, Fair K, Hong YA, Beaudoin CE, Pulczinski J, Ory MG. Apps seeking theories: results of a study on the use of health behavior change theories in cancer survivorship mobile apps. JMIR Mhealth Uhealth 2015 Mar 27;3(1):e31 [FREE Full text] [doi: 10.2196/mhealth.3861] [Medline: 25830810]

16. Monteiro-Guerra F, Rivera-Romero O, Fernandez-Luque L, Caulfield B. Personalization in real-time physical activity coaching using mobile applications: a scoping review. IEEE J Biomed Health Inform 2020 Jun;24(6):1738-1751. [doi: 10.1109/jbhi.2019.2947243]

17. Cho YM, Lee S, Islam SMS, Kim SY. Theories applied to m-Health interventions for behavior change in low- and middle-income countries: a systematic review. Telemed J E Health 2018 Oct;24(10):727-741 [FREE Full text] [doi: 10.1089/tmj.2017.0249] [Medline: 29437546]

18. Chib A, Lin SH. Theoretical advancements in mHealth: a systematic review of mobile apps. J Health Commun 2018 Nov 19;23(10-11):909-955. [doi: 10.1080/10810730.2018.1544676] [Medline: $\underline{\text { 30449261] }}$

19. Winter SJ, Sheats JL, King AC. The use of behavior change techniques and theory in technologies for cardiovascular disease prevention and treatment in adults: a comprehensive review. Prog Cardiovasc Dis 2016;58(6):605-612 [FREE Full text] [doi: 10.1016/j.pcad.2016.02.005] [Medline: 26902519]

20. Davis R, Campbell R, Hildon Z, Hobbs L, Michie S. Theories of behaviour and behaviour change across the social and behavioural sciences: a scoping review. Health Psychol Rev 2015;9(3):323-344 [FREE Full text] [doi: 10.1080/17437199.2014.941722] [Medline: 25104107]

21. Webb TL, Joseph J, Yardley L, Michie S. Using the internet to promote health behavior change: a systematic review and meta-analysis of the impact of theoretical basis, use of behavior change techniques, and mode of delivery on efficacy. J Med Internet Res 2010 Feb 17;12(1):e4 [FREE Full text] [doi: 10.2196/jmir.1376] [Medline: 20164043]

22. Glanz K, Bishop DB. The role of behavioral science theory in development and implementation of public health interventions. Annu Rev Public Health 2010;31:399-418. [doi: 10.1146/annurev.publhealth.012809.103604] [Medline: 20070207]

23. Taylor N, Conner M, Lawton R. The impact of theory on the effectiveness of worksite physical activity interventions: a meta-analysis and meta-regression. Health Psychol Rev 2012 Mar;6(1):33-73. [doi: 10.1080/17437199.2010.533441]

24. Prestwich A, Sniehotta FF, Whittington C, Dombrowski SU, Rogers L, Michie S. Does theory influence the effectiveness of health behavior interventions? Meta-analysis. Health Psychol 2014 May;33(5):465-474. [doi: 10.1037/a0032853] [Medline: 23730717]

25. Garnett C, Crane D, Brown J, Kaner E, Beyer F, Muirhead C, et al. Reported theory use by digital interventions for hazardous and harmful alcohol consumption, and association with effectiveness: meta-regression. J Med Internet Res 2018 Feb 28;20(2):e69 [FREE Full text] [doi: 10.2196/jmir.8807] [Medline: 29490895]

26. Gardner B, Wardle J, Poston L, Croker H. Changing diet and physical activity to reduce gestational weight gain: a meta-analysis. Obes Rev 2011 Jul;12(7):602-620. [doi: 10.1111/j.1467-789X.2011.00884.x] [Medline: 21521451]

27. Hagger MS, Weed M. DEBATE: do interventions based on behavioral theory work in the real world? Int J Behav Nutr Phys Act 2019 Apr 25;16(1):36 [FREE Full text] [doi: 10.1186/s12966-019-0795-4] [Medline: $\underline{31023328]}$

28. Gainforth HL, West R, Michie S. Assessing connections between behavior change theories using network analysis. Ann Behav Med 2015 Oct 22;49(5):754-761. [doi: 10.1007/s12160-015-9710-7] [Medline: 26002108]

29. Prochaska JO, DiClemente CC. Transtheoretical therapy: toward a more integrative model of change. Psychotherapy: Theory, Res, and Practice 1982;19(3):276-288. [doi: 10.1037/h0088437]

30. Ajzen I. The theory of planned behavior. Organ Behav Hum Decis Process 1991 Dec;50(2):179-211. [doi: 10.1016/0749-5978(91)90020-T]

31. Bandura A. Human agency in social cognitive theory. Am Psychol 1989;44(9):1175-1184. [doi: 10.1037/0003-066X.44.9.1175]

32. Scholz U. It's time to think about time in health psychology. Appl Psychol Health Well Being 2019 Jul 10;11(2):173-186. [doi: 10.1111/aphw.12156] [Medline: 30972951]

33. Rothman AJ. It's about time: answering the call for greater precision in research and practice. Appl Psychol Health Well Being 2019 Jul 10;11(2):191-197. [doi: 10.1111/aphw.12158] [Medline: 30972957]

34. Michie S, West R, Spring B. Moving from theory to practice and back in social and health psychology. Health Psychol 2013 May;32(5):581-585. [doi: 10.1037/a0030205] [Medline: 23646841] 
35. Postman L. The history and present status of the law of effect. Psychol Bull 1947 Nov;44:489-563. [doi: 10.1037/h0057716] [Medline: 20273420]

36. Yin HH, Knowlton BJ. The role of the basal ganglia in habit formation. Nat Rev Neurosci 2006 Jun;7(6):464-476. [doi: 10.1038/nrn1919] [Medline: 16715055]

37. Sutton RS, Barto AG. Reinforcement learning: an introduction. Cambridge, Mass: MIT press; 2018:A.

38. Thorndike EL. The fundamentals of learning. New York: Teachers College Bureau of Publications; 1932.

39. Dickinson A. Actions and habits: the development of behavioural autonomy. Phil Trans R Soc Lond B 1997 Jan 13;308(1135):67-78. [doi: 10.1098/rstb.1985.0010]

40. Wood W, Neal DT. A new look at habits and the habit-goal interface. Psychol Rev 2007;114(4):843-863. [doi: 10.1037/0033-295x.114.4.843]

41. Wood W, Rünger D. Psychology of habit. Annu Rev Psychol 2016;67:289-314. [doi: 10.1146/annurev-psych-122414-033417] [Medline: 26361052]

42. Verplanken B. Psychology of habit. Cham, Switzerland: Springer; 2018.

43. Gardner B. A review and analysis of the use of 'habit' in understanding, predicting and influencing health-related behaviour. Health Psychol Rev 2015 Jan 21;9(3):277-295 [FREE Full text] [doi: 10.1080/17437199.2013.876238] [Medline: 25207647]

44. Kanfer FH, Karoly P. Self-control: a behavioristic excursion into the lion's den. Behavior Therapy 1972 Jul;3(3):398-416. [doi: 10.1016/s0005-7894(72)80140-0]

45. Carver CS, Scheier MF. Control theory: a useful conceptual framework for personality-social, clinical, and health psychology. Psychol Bull 1982;92(1):111-135. [doi: 10.1037/0033-2909.92.1.111]

46. Powers WT. Feedback: beyond behaviorism. Science 1973 Jan 26;179(4071):351-356. [doi: 10.1126/science.179.4071.351] [Medline: $\underline{4682961]}$

47. Norman DA, Shallice T. Attention to action. In: Consciousness and self-regulation. Boston: Springer; 1986:1-18.

48. Psarra I. A bounded rationality model of short and long-term dynamics of activity-travel behavior (Bouwstenen 213 ed). Eindhoven, NL: Technische Universiteit Eindhoven; 2016.

49. Bandura A. Social learning theory. Morristown, NJ: General Learning Press; 1971. URL: https://www.worldcat.org/title/ social-learning-theory/oclc/691872 [accessed 2021-03-29]

50. Bandura A. Self-efficacy mechanism in human agency. Am Psychol 1982;37(2):122-147. [doi: 10.1037/0003-066X.37.2.122]

51. Bandura A, McDonald FJ. Influence of social reinforcement and the behavior of models in shaping children's moral judgment. J Abnorm Soc Psychol 1963;67(3):274-281. [doi: 10.1037/h0044714] [Medline: 14054361]

52. Bandura A, Wood R. Effect of perceived controllability and performance standards on self-regulation of complex decision making. J Pers Soc Psychol 1989 May;56(5):805-814. [doi: 10.1037//0022-3514.56.5.805] [Medline: 2724068]

53. Oppenheimer DM, Kelso E. Information processing as a paradigm for decision making. Annu Rev Psychol 2015 Jan 03;66(1):277-294. [doi: 10.1146/annurev-psych-010814-015148] [Medline: 25559114]

54. Savage LJ. The foundations of statistics. New York: Wiley; 1954.

55. von Neumann J, Morgenstern O. Theory of games and economic behavior, 2nd rev. Princeton, NJ: Princeton University Press; 1947.

56. Busemeyer JR, Townsend JT. Decision field theory: a dynamic-cognitive approach to decision making in an uncertain environment. Psychol Rev 1993;100(3):432-459. [doi: 10.1037//0033-295x.100.3.432]

57. Bhatia S. Associations and the accumulation of preference. Psychol Rev 2013 Jul;120(3):522-543. [doi: 10.1037/a0032457] [Medline: 23607600]

58. Tversky A. Elimination by aspects: a theory of choice. Psychol Rev 1972;79(4):281-299. [doi: 10.1037/h0032955]

59. Tversky A, Kahneman D. The framing of decisions and the psychology of choice. Science 1981 Jan 30;211(4481):453-458. [doi: 10.1126/science.7455683] [Medline: 7455683]

60. Roe RM, Busemeyer JR, Townsend JT. Multialternative decision field theory: a dynamic connectionst model of decision making. Psychol Rev 2001;108(2):370-392. [doi: 10.1037//0033-295x.108.2.370]

61. Ratcliff R, Rouder JN. Modeling response times for two-choice decisions. Psychol Sci 2016 May 06;9(5):347-356. [doi: 10.1111/1467-9280.00067]

62. Fishbein M, Ajzen I. Belief, attitude, intention, and behavior: an introduction to theory and research. Boston: Addison-Wesley; 1975:A.

63. Head KJ, Noar SM. Facilitating progress in health behaviour theory development and modification: the reasoned action approach as a case study. Health Psychol Rev 2014 Mar 18;8(1):34-52. [doi: 10.1080/17437199.2013.778165] [Medline: 25053006]

64. Ajzen I, Madden TJ. Prediction of goal-directed behavior: attitudes, intentions, and perceived behavioral control. J Exp Soc Psychol 1986 Sep;22(5):453-474. [doi: 10.1016/0022-1031(86)90045-4]

65. Janz NK, Becker MH. The health belief model: a decade later. Health Educ Q 1984 Jan 01;11(1):1-47. [doi: 10.1177/109019818401100101] [Medline: 6392204]

66. Karoly P. Mechanisms of self-regulation: a systems view. Annu Rev Psychol 1993 Jan;44(1):23-52. [doi: 10.1146/annurev.ps.44.020193.000323] 
67. De Bruijn GJ, Kremers SPJ, De Vet E, De Nooijer J, Van Mechelen M, Brug J. Does habit strength moderate the intention-behaviour relationship in the Theory of Planned Behaviour? The case of fruit consumption. Psychol Health 2007 Dec;22(8):899-916. [doi: $10.1080 / 14768320601176113$ ]

68. Evans JSBT. Dual-processing accounts of reasoning, judgment, and social cognition. Annu Rev Psychol 2008 Jan;59(1):255-278. [doi: 10.1146/annurev.psych.59.103006.093629] [Medline: 18154502]

69. Kahneman D. A perspective on judgment and choice: mapping bounded rationality. Am Psychol 2003;58(9):697-720. [doi: 10.1037/0003-066x.58.9.697]

70. Strack F, Deutsch R. Reflective and impulsive determinants of social behavior. Pers Soc Psychol Rev 2004 Dec 21;8(3):220-247. [doi: $10.1207 / \mathrm{s} 15327957$ pspr0803 1] [Medline: 15454347$]$

71. Hofmann W, Friese M, Wiers RW. Impulsive versus reflective influences on health behavior: a theoretical framework and empirical review. Health Psychol Rev 2008 Sep;2(2):111-137. [doi: 10.1080/17437190802617668]

72. Hofmann W, Friese M, Strack F. Impulse and self-control from a dual-systems perspective. Perspect Psychol Sci 2009 Mar;4(2):162-176. [doi: 10.1111/j.1745-6924.2009.01116.x] [Medline: 26158943]

73. Kamphorst B, Kalis A. Why option generation matters for the design of autonomous e-coaching systems. AI \& Soc 2014 Jan 17;30(1):77-88. [doi: 10.1007/s00146-013-0532-5]

74. Tobias R. Changing behavior by memory aids: a social psychological model of prospective memory and habit development tested with dynamic field data. Psychol Rev 2009 Apr;116(2):408-438. [doi: 10.1037/a0015512] [Medline: 19348548]

75. McDaniel MA, Einstein GO. Strategic and automatic processes in prospective memory retrieval: a multiprocess framework. Appl Cognit Psychol 2001;14(7):127-144. [doi: 10.1002/acp.775]

76. Gollwitzer PM. Implementation intentions: strong effects of simple plans. Am Psychol 1999;54(7):493-503. [doi: 10.1037/0003-066X.54.7.493]

77. Epstein LH, Temple JL, Roemmich JN, Bouton ME. Habituation as a determinant of human food intake. Psychol Rev 2009 Apr;116(2):384-407 [FREE Full text] [doi: 10.1037/a0015074] [Medline: 19348547]

78. Berkman ET, Hutcherson CA, Livingston JL, Kahn LE, Inzlicht M. Self-control as value-based choice. Curr Dir Psychol Sci 2017 Oct 09;26(5):422-428 [FREE Full text] [doi: 10.1177/0963721417704394] [Medline: 29335665]

79. Frederick S, Loewenstein G, O'donoghue T. Time discounting and time preference: a critical review. J Econ Lit 2002 Jun;40(2):351-401. [doi: 10.1257/jel.40.2.351]

80. Green L, Myerson J. A discounting framework for choice with delayed and probabilistic rewards. Psychol Bull 2004 Sep;130(5):769-792 [FREE Full text] [doi: 10.1037/0033-2909.130.5.769] [Medline: 15367080]

81. Chapman GB. Temporal discounting and utility for health and money. J Experimental Psychol: Learning, Memory, and Cognition 1996;22(3):771-791. [doi: 10.1037//0278-7393.22.3.771]

82. Story GW, Vlaev I, Seymour B, Darzi A, Dolan RJ. Does temporal discounting explain unhealthy behavior? A systematic review and reinforcement learning perspective. Front Behav Neurosci 2014 Mar 12;8:76 [FREE Full text] [doi: 10.3389/fnbeh.2014.00076] [Medline: 24659960]

83. Maier SU, Beharelle AR, Polanía R, Ruff CC, Hare TA. Dissociable mechanisms govern when and how strongly reward attributes affect decisions. Nat Hum Behav 2020 Sep;4(9):949-963. [doi: 10.1038/s41562-020-0893-y] [Medline: 32483344]

84. Sullivan NJ, Huettel SA. Dietary self-control depends on the latency and rate of information accumulation. Cold Spirng Harbor Laboratory 2018:1 [FREE Full text] [doi: 10.1101/465393]

85. Sullivan N, Hutcherson C, Harris A, Rangel A. Dietary self-control is related to the speed with which attributes of healthfulness and tastiness are processed. Psychol Sci 2015 Feb 16;26(2):122-134 [FREE Full text] [doi: 10.1177/0956797614559543] [Medline: 25515527]

86. Zhang C, Willemsen M, Lakens D. Can mouse-tracking reveal attribute processing speeds in dietary self-control? Commentary on Sullivan et al. (2015) and Lim et al. (2018) with a simulation study. Psyarxiv Prints 2018:1-19. [doi: 10.31234/osf.io/725vp]

87. Hare TA, Camerer CF, Rangel A. Self-control in decision-making involves modulation of the vmPFC valuation system. Science 2009 May 01;324(5927):646-648 [FREE Full text] [doi: 10.1126/science.1168450] [Medline: 19407204]

88. Harris A, Hare T, Rangel A. Temporally dissociable mechanisms of self-control: early attentional filtering versus late value modulation. J Neurosci 2013 Nov 27;33(48):18917-18931. [doi: 10.1523/jneurosci.5816-12.2013]

89. Inzlicht M, Schmeichel BJ. What is ego depletion? Toward a mechanistic revision of the resource model of self-control. Perspect Psychol Sci 2012 Sep 05;7(5):450-463. [doi: 10.1177/1745691612454134] [Medline: 26168503]

90. van der Linden D, Frese M, Meijman TF. Mental fatigue and the control of cognitive processes: effects on perseveration and planning. Acta Psychologica 2003 May;113(1):45-65. [doi: 10.1016/s0001-6918(02)00150-6]

91. Chajut E, Algom D. Selective attention improves under stress: implications for theories of social cognition. J Pers Soc Psychol 2003 Aug;85(2):231-248. [doi: 10.1037/0022-3514.85.2.231] [Medline: 12916567]

92. Zhang C, Smolders KC, Lakens D, IJsselsteijn WA. Two experience sampling studies examining the variation of self-control capacity and its relationship with core affect in daily life. J Res Pers 2018 Jun;74:102-113. [doi: 10.1016/j.jrp.2018.03.001]

93. Russo DJ, Van Roy B, Kazerouni A, Osband I, Wen Z. A tutorial on Thompson sampling. FNT in Machine Learning 2018;11(1):1-96. [doi: 10.1561/2200000070] 
94. Gershman SJ, Daw ND. Reinforcement learning and episodic memory in humans and animals: an integrative framework. Annu Rev Psychol 2017 Jan 03;68(1):101-128 [FREE Full text] [doi: 10.1146/annurev-psych-122414-033625] [Medline: 27618944]

95. Klein MC, Mogles N, Treur J, van Wissen A. A computational model of habit learning to enable ambient support for lifestyle change. In: Modern Approaches in Applied Intelligence. Berlin: Springer; 2011:130-142.

96. Miller KJ, Shenhav A, Ludvig EA. Habits without values. Psychol Rev 2019 Mar;126(2):292-311 [FREE Full text] [doi: 10.1037/rev0000120] [Medline: 30676040]

97. Crutzen R, Peters GY. Evolutionary learning processes as the foundation for behaviour change. Health Psychol Rev 2018 Mar 18;12(1):43-57. [doi: 10.1080/17437199.2017.1362569] [Medline: 28764599]

98. Raynor HA, Epstein LH. Dietary variety, energy regulation, and obesity. Psychol Bull 2001 May;127(3):325-341. [doi: 10.1037/0033-2909.127.3.325] [Medline: 11393299]

99. Trope Y, Liberman N. Construal-level theory of psychological distance. Psychol Rev 2010 Apr;117(2):440-463 [FREE Full text] [doi: 10.1037/a0018963] [Medline: 20438233]

100. Locke EA, Latham GP. Building a practically useful theory of goal setting and task motivation: a 35-year odyssey. Am Psychol 2002 Sep;57(9):705-717. [doi: 10.1037/0003-066X.57.9.705]

101. Abraham C, Michie S. A taxonomy of behavior change techniques used in interventions. Health Psychol 2008 May;27(3):379-387. [doi: 10.1037/0278-6133.27.3.379] [Medline: $\underline{18624603}$ ]

102. Kok G, Gottlieb NH, Peters GJY, Mullen PD, Parcel GS, Ruiter RAC, et al. A taxonomy of behaviour change methods: an Intervention Mapping approach. Health Psychol Rev 2016 Sep;10(3):297-312 [FREE Full text] [doi: 10.1080/17437199.2015.1077155] [Medline: 26262912]

103. Michie S, Carey RN, Johnston M, Rothman AJ, de Bruin M, Kelly MP, et al. From theory-inspired to theory-based interventions: a protocol for developing and testing a methodology for linking behaviour change techniques to theoretical mechanisms of action. Ann Behav Med 2018 May 18;52(6):501-512 [FREE Full text] [doi: 10.1007/s12160-016-9816-6] [Medline: 27401001]

104. Hekler EB, Michie S, Pavel M, Rivera DE, Collins LM, Jimison HB, et al. Advancing models and theories for digital behavior change interventions. Am J Prev Med 2016 Nov;51(5):825-832 [FREE Full text] [doi: 10.1016/j.amepre.2016.06.013] [Medline: 27745682]

105. Intille SS, Kukla C, Farzanfar R, Bakr W. Just-in-time technology to encourage incremental, dietary behavior change. AMIA Annu Symp Proc 2003:874 [FREE Full text] [Medline: 14728379]

106. Jaimes LG, Calderon J, Lopez J, Raij A. Trends in mobile cyber-physical systems for health just-in time interventions. In: Proceedings of SoutheastCon 2015. 2015 Presented at: SoutheastCon 2015; April 9-12, 2015; Fort Lauderdale, FL, USA p. 1-6. [doi: 10.1109/SECON.2015.7132887]

107. Nahum-Shani I, Hekler EB, Spruijt-Metz D. Building health behavior models to guide the development of just-in-time adaptive interventions: a pragmatic framework. Health Psychol 2015 Dec;34S:1209-1219 [FREE Full text] [doi: 10.1037/hea0000306] [Medline: 26651462]

108. Riley WT, Serrano KJ, Nilsen W, Atienza AA. Mobile and wireless technologies in health behavior and the potential for intensively adaptive interventions. Curr Opin Psychol 2015 Oct 01;5:67-71 [FREE Full text] [doi: 10.1016/j.copsyc.2015.03.024] [Medline: 26086033]

109. Pina L, Ramirez E, Griswold WG. Fitbit+: A behavior-based intervention system to reduce sedentary behavior. In: Proceedings of the 6th International Conference on Pervasive Computing Technologies for Healthcare. 2012 Presented at: 6th International Conference on Pervasive Computing Technologies for Healthcare; May 21-24. 2012; San Diego, CA, USA p. $175-178$. [doi: 10.4108/icst.pervasivehealth.2012.248761]

110. Thomas JG, Bond DS. Behavioral response to a just-in-time adaptive intervention (JITAI) to reduce sedentary behavior in obese adults: implications for JITAI optimization. Health Psychol 2015 Dec;34S(Suppl):1261-1267 [FREE Full text] [doi: 10.1037/hea0000304] [Medline: 26651467]

111. Guo L. Quantified-self 2.0: using context-aware services for promoting gradual behaviour change. arXiv:1610.00460. 2016. URL: https://arxiv.org/abs/1610.00460 [accessed 2021-03-17]

112. Adams AT, Costa J, Jung M, Choudhury T. Mindless computing: designing technologies to subtly influence behavior. In: Proceedings of the 2015 ACM International Joint Conference on Pervasive and Ubiquitous Computing. 2015 Presented at: UbiComp '15: The 2015 ACM International Joint Conference on Pervasive and Ubiquitous Computing; September, 2015; Osaka Japan p. 719-730. [doi: 10.1145/2750858.2805843]

113. Schneider C, Weinmann M, vom Brocke J. Digital nudging: guiding online user choices through interface design. Commun ACM 2018 Jun 25;61(7):67-73 [FREE Full text] [doi: 10.1145/3213765]

114. Johnson EJ, Shu SB, Dellaert BGC, Fox C, Goldstein DG, Häubl G, et al. Beyond nudges: tools of a choice architecture. Mark Lett 2012 May 25;23(2):487-504. [doi: 10.1007/s11002-012-9186-1]

115. Thaler RH, Sunstein CR. Nudge: improving decisions about health, wealth, and happiness. New Haven, Connecticut, United States: Yale University Press; 2008:1-293.

116. Johnson EJ, Goldstein D. Medicine. Do defaults save lives? Science 2003 Nov 21;302(5649):1338-1339. [doi: 10.1126/science.1091721] [Medline: 14631022] 
117. Lee MK, Kiesler S, Forlizzi J. Mining behavioral economics to design persuasive technology for healthy choices. In: Proceedings of the SIGCHI Conference on Human Factors in Computing Systems. 2011 Presented at: SIGCHI Conference on Human Factors in Computing Systems; May, 2011; Vancouver, BC, Canada p. 325-334. [doi: 10.1145/1978942.1978989]

118. Zhang C, Starczewski A, Lakens D, IJsselsteijn W. A Decision-Making Perspective on Coaching Behavior Change: A Field Experiment on Promoting Exercise at Work. In: Persuasive Technology. Switzerland: Springer; 2018:87-98.

119. Rahman T, Czerwinski M, Gilad-Bachrach R, Johns P. Predicting about-to-eat moments for just-in-time eating intervention. In: Proceedings of the 6th International Conference on Digital Health Conference. 2016 Presented at: 6th International Conference on Digital Health Conference; April 2016; Montréal Québec Canada p. 141-150. [doi: 10.1145/2896338.2896359]

120. Jaimes LG, Llofriu M, Raij A. A stress-free life: just-in-time interventions for stress via real-time forecasting and intervention adaptation. In: Proceedings of the 9th International Conference on Body Area Networks. 2014 Presented at: 9th International Conference on Body Area Networks; Sep 29th - Oct 1st, 2014; London, Great Britain p. 197-203. [doi:

10.4108/icst.bodynets.2014.258237]

121. Zuboff S. The age of surveillance capitalism: the fight for a human future at the new frontier of power. New York: Profile Books; 2019:-.

122. Kersten-van Dijk ET, Westerink JH, Beute F, IJsselsteijn WA. Personal informatics, self-insight, and behavior change: a critical review of current literature. Hum Comput Interact 2017 Feb 17;32(5-6):268-296. [doi: $10.1080 / 07370024.2016 .1276456]$

123. Choe EK, Lee NB, Lee B, Pratt W, Kientz JA. Understanding quantified-selfers' practices in collectingexploring personal data. In: Proceedings of the SIGCHI Conference on Human Factors in Computing Systems. 2014 Presented at: SIGCHI Conference on Human Factors in Computing Systems; April, 2014; Toronto Ontario Canada p. 1143-1152. [doi: $10.1145 / 2556288.2557372]$

124. Li I, Dey AK, Forlizzi J. Understanding my data, myself: supporting self-reflection with ubicomp technologies. In: Proceedings of the 13th international conference on Ubiquitous computing. 2011 Presented at: UbiComp '11: Proceedings of the 13th international conference on Ubiquitous computing; September 2011; Beijing China p. 405-414. [doi: 10.1145/2030112.2030166]

125. Nacke LE, Deterding S. The maturing of gamification research. Comput Hum Behav 2017 Jun;71:450-454. [doi: 10.1016/j.chb.2016.11.062]

126. Cugelman B. Gamification: what it is and why it matters to digital health behavior change developers. JMIR Serious Games 2013 Dec 12;1(1):e3 [FREE Full text] [doi: 10.2196/games.3139] [Medline: 25658754]

127. Deterding S, Dixon D, Khaled R, Nacke L. From game design elements to gamefulness: defining "gamification". In: Proceedings of the 15th International Academic MindTrek Conference: Envisioning Future Media Environments. 2011 Presented at: MindTrek '11: 15th International Academic MindTrek Conference: Envisioning Future Media Environments; September, 2011; Tampere Finland p. 9-15. [doi: 10.1145/2181037.2181040]

128. Zuckerman O, Gal-Oz A. Deconstructing gamification: evaluating the effectiveness of continuous measurement, virtual rewards, and social comparison for promoting physical activity. Pers Ubiquit Comput 2014 Jul 5;18(7):1705-1719. [doi: 10.1007/s00779-014-0783-2]

129. Munson SA, Consolvo S. Exploring goal-setting, rewards, self-monitoring,sharing to motivate physical activity. In: Proceedings of the 6th International Conference on Pervasive Computing Technologies for Healthcare. 2012 Presented at: 6th International Conference on Pervasive Computing Technologies for Healthcare; May 21-24, 2012; San Diego, United States p. 25-32. [doi: 10.4108/icst.pervasivehealth.2012.248691]

130. DeSmet A, Shegog R, Van Ryckeghem D, Crombez G, De Bourdeaudhuij I. A systematic review and meta-analysis of interventions for sexual health promotion involving serious digital games. Games Health J 2015 Apr;4(2):78-90. [doi: 10.1089/g4h.2014.0110] [Medline: 26181801]

131. Nicholson $\mathrm{S}$. Two paths to motivation through game design elements: reward-based gamification and meaningful gamification. Proceedings of iConference. 2013. URL: https://core.ac.uk/download/pdf/10202074.pdf [accessed 2021-03-17]

132. Berkovsky S, Coombe M, Freyne J, Bhandari D, Baghaei N. Physical activity motivating games: virtual rewards for real activity. In: Proceedings of the SIGCHI Conference on Human Factors in Computing Systems. 2010 Presented at: CHI '10: SIGCHI Conference on Human Factors in Computing Systems; April 2010; Atlanta Georgia USA p. 243-252. [doi: $10.1145 / 1753326.1753362]$

133. Novak JI, Loy J. A pilot study for utilizing additive manufacturing and responsive rewards in physical activity gamification. Design for Health 2019 Jan 12;2(2):266-284. [doi: 10.1080/24735132.2018.1541400]

134. Meder M, Plumbaum T, Raczkowski A, Jain B, Albayrak S. Gamification in e-commerce: tangible vs. intangible rewards. In: Proceedings of the 22nd International Academic Mindtrek Conference. 2018 Presented at: Mindtrek '18: 22nd International Academic Mindtrek Conference; October 2018; Tampere Finland p. 11-19. [doi: 10.1145/3275116.3275126]

135. Shahrestani A, Van Gorp P, Le BP, Greidanus F, De GK, Leermakers J. Unified Health Gamification can significantly improve well-being in corporate environments. In: Proceedings of the 39th Annual International Conference of the IEEE Engineering in Medicine and Biology Society (EMBC). 2017 Presented at: 39th Annual International Conference of the IEEE Engineering in Medicine and Biology Society (EMBC); July 11-15, 2017; Jeju, Korea (South) p. 4507-4511. [doi: 10.1109/embc.2017.8037858] 
136. Saksono H, Castaneda-Sceppa C, Hoffman J, Morris V, Seif EM, Parker A. Storywell: designing for family fitness app motivation by using social rewards and reflection. In: Proceedings of the 2020 CHI Conference on Human Factors in Computing Systems. 2020 Presented at: 2020 CHI Conference on Human Factors in Computing Systems; April 2020; Honolulu HI USA p. 1-13. [doi: 10.1145/3313831.3376686]

137. Armstrong AW, Watson AJ, Makredes M, Frangos JE, Kimball AB, Kvedar JC. Text-message reminders to improve sunscreen use: a randomized, controlled trial using electronic monitoring. Arch Dermatol 2009;145(11):1230-1236. [doi: 10.1001/archdermatol.2009.269] [Medline: 19917951]

138. Thakkar J, Kurup R, Laba T, Santo K, Thiagalingam A, Rodgers A, et al. Mobile telephone text messaging for medication adherence in chronic disease: a meta-analysis. JAMA Intern Med 2016 Mar;176(3):340-349. [doi: 10.1001/jamainternmed.2015.7667] [Medline: 26831740]

139. Kolb DA, Boyatzis RE. Goal-setting and self-directed behavior change. Hum Relat 2016 Apr 22;23(5):439-457. [doi: $\underline{10.1177 / 001872677002300506]}$

140. Radha M, Willemsen MC, Boerhof M, IJsselsteijn WA. Lifestyle recommendations for hypertension through Rasch-based feasibility modeling. In: Proceedings of the 2016 Conference on User Modeling Adaptation and Personalization. 2016 Presented at: UMAP '16: Proceedings of the 2016 Conference on User Modeling Adaptation and Personalization; July 2016; Halifax Nova Scotia p. 239-247. [doi: 10.1145/2930238.2930251]

141. Rutjes H, Willemsen MC, IJsselsteijn WA. Beyond behavior: the coach's perspective on technology in health coaching. In: Proceedings of the 2019 CHI Conference on Human Factors in Computing Systems. 2019 Presented at: CHI '19: CHI Conference on Human Factors in Computing Systems; May 2019; Glasgow, Scotland, UK p. 1-14. [doi: $10.1145 / 3290605.3300900]$

142. Zhou M, Mintz Y, Fukuoka Y, Goldberg K, Flowers E, Kaminsky P, et al. Personalizing mobile fitness apps using reinforcement learning. CEUR Workshop Proc 2018 Mar 07;2068:- [FREE Full text] [Medline: $\underline{32405286}$ ]

143. Geurts E, Van Geel , F, Feys P, Coninx K. WalkWithMe: personalized goal setting and coaching for walking in people with multiple sclerosis. In: Proceedings of the 27th ACM Conference on User Modeling, Adaptation and Personalization. 2019 Presented at: 7th ACM Conference on User Modeling, Adaptation and Personalization; June 2019; Larnaca Cyprus p. 51-60. [doi: $10.1145 / 3320435.3320459$ ]

144. Chokshi NP, Adusumalli S, Small DS, Morris A, Feingold J, Ha YP, et al. Loss - framed financial incentives and personalized goal - setting to increase physical activity among ischemic heart disease patients using wearable devices: The ACTIVE REWARD randomized trial. J Am Heart Assoc 2018 Jun 19;7(12):-. [doi: 10.1161/jaha.118.009173]

145. Adriaanse MA, Vinkers CD, De Ridder DT, Hox JJ, De Wit JB. Do implementation intentions help to eat a healthy diet? A systematic review and meta-analysis of the empirical evidence. Appetite 2011 Feb;56(1):183-193 [FREE Full text] [doi: 10.1016/j.appet.2010.10.012] [Medline: 21056605]

146. Stawarz KM. Towards better medication adherence apps: preventing forgetfulness by facilitating the formation of routine-based remembering strategies. University College London. 2017. URL: https://discovery.ucl.ac.uk/id/eprint/1546254/ [accessed 2021-03-17]

147. Luszczynska A, Sobczyk A, Abraham C. Planning to lose weight: randomized controlled trial of an implementation intention prompt to enhance weight reduction among overweight and obese women. Health Psychol 2007 Jul;26(4):507-512. [doi: 10.1037/0278-6133.26.4.507] [Medline: 17605571]

148. Pinder C, Vermeulen J, Wicaksono A, Beale R, Hendley RJ. If this, then habit exploring context-aware implementation intentions on smartphones. In: Proceedings of the 18th International Conference on Human-Computer Interaction with Mobile Devices and Services Adjunct. 2016 Presented at: MobileHCI '16: 18th International Conference on Human-Computer Interaction with Mobile Devices and Services Adjunct; 2016; Florence Italy p. 690-697. [doi: 10.1145/2957265.2961837]

149. Dogangün A, Schwarz M, Kloppenborg K, Le R. An approach to improve physical activity by generating individual implementation intentions. In: Proceedings of the 25th Conference on User Modeling, Adaptation and Personalization. 2017 Presented at: UMAP '17: Adjunct Publication of the 25th Conference on User Modeling, Adaptation and Personalization; July, 2017; Bratislava Slovakia p. 370-375. [doi: 10.1145/3099023.3099101]

150. Lehto T, Oinas-Kukkonen H. Persuasive features in web-based alcohol and smoking interventions: a systematic review of the literature. J Med Internet Res 2011 Jul 22;13(3):e46 [FREE Full text] [doi: 10.2196/jmir.1559] [Medline: 21795238]

151. Mercer K, Li M, Giangregorio L, Burns C, Grindrod K. Behavior change techniques present in wearable activity trackers: a critical analysis. JMIR Mhealth Uhealth 2016 Apr 27;4(2):e40 [FREE Full text] [doi: 10.2196/mhealth.4461] [Medline: 27122452]

152. Payne HE, Lister C, West JH, Bernhardt JM. Behavioral functionality of mobile apps in health interventions: a systematic review of the literature. JMIR Mhealth Uhealth 2015 Feb 26;3(1):e20 [FREE Full text] [doi: 10.2196/mhealth.3335] [Medline: 25803705]

153. Zhao J, Freeman B, Li M. Can mobile phone apps influence people's health behavior change? An evidence review. J Med Internet Res 2016 Oct 31;18(11):e287 [FREE Full text] [doi: 10.2196/jmir.5692] [Medline: 27806926]

154. Michie S, Abraham C, Whittington C, McAteer J, Gupta S. Effective techniques in healthy eating and physical activity interventions: a meta-regression. Health Psychol 2009 Nov;28(6):690-701. [doi: 10.1037/a0016136] [Medline: 19916637] 
155. Hermsen S, Frost J, Renes RJ, Kerkhof P. Using feedback through digital technology to disrupt and change habitual behavior: a critical review of current literature. Comput Hum Behav 2016 Apr;57:61-74. [doi: 10.1016/j.chb.2015.12.023]

156. van Dijk ET, Westerink JHDM, Beute F, IJsselsteijn WA. In sync: the effect of physiology feedback on the match between heart rate and self-reported stress. Biomed Res Int 2015;2015:- [FREE Full text] [doi: 10.1155/2015/134606] [Medline: 26146611]

157. Klein M, Mogles N, van Wissen A. Why won't you do what's good for you? Using intelligent support for behavior change. In: Human Behavior Understanding. Berlin, Heidelberg: Springer; 2011:104-115.

158. Klein M, Mogles N, van Wissen A. Intelligent mobile support for therapy adherence and behavior change. J Biomed Inform 2014 Oct;51:137-151 [FREE Full text] [doi: 10.1016/j.jbi.2014.05.005] [Medline: 24858491]

159. de Vries H. An integrated approach for understanding health behavior; the I-change model as an example. Psychol Behav Sci Inter J 2017 Mar 9;2(2):-. [doi: 10.19080/pbsij.2017.02.555585]

160. Riley WT, Martin CA, Rivera DE, Hekler EB, Adams MA, Buman MP, et al. Development of a dynamic computational model of social cognitive theory. Transl Behav Med 2016 Dec;6(4):483-495 [FREE Full text] [doi: 10.1007/s13142-015-0356-6] [Medline: 27848208]

161. Zhang C, Vanschoren J, van Wissen A, Lakens D, de RB, IJsselsteijn WA. Theory-based habit modeling for enhancing behavior prediction in behavior change support systems. Manuscript in preparation 2021:- Manuscript in preparation.

162. West R. Theory of addiction. Oxford, UK: Blackwell; 2006.

163. Hall PA, Fong GT. Temporal self-regulation theory: a model for individual health behavior. Health Psychol Rev 2007 Mar;1(1):6-52. [doi: 10.1080/17437190701492437]

164. Vlaev I, Dolan P. Action change theory: a reinforcement learning perspective on behavior change. Rev Gen Psychol 2015 Mar;19(1):69-95. [doi: 10.1037/gpr0000029]

165. Hastie R. Problems for judgment and decision making. Annu Rev Psychol 2001 Feb;52(1):653-683. [doi: 10.1146/annurev.psych.52.1.653] [Medline: 11148321]

166. Dolan RJ, Dayan P. Goals and habits in the brain. Neuron 2013 Oct 16;80(2):312-325 [FREE Full text] [doi: 10.1016/j.neuron.2013.09.007] [Medline: 24139036]

167. Heckhausen J. The motivation-volition divide and its resolution in action-phase models of developmental regulation. Res Hum Dev 2007 Nov 14;4(3-4):163-180. [doi: 10.1080/15427600701662983]

168. Heckhausen H, Gollwitzer PM. Thought contents and cognitive functioning in motivational versus volitional states of mind. Motiv Emot 1987 Jun;11(2):101-120. [doi: 10.1007/bf00992338]

169. Usher M, McClelland JL. The time course of perceptual choice: the leaky, competing accumulator model. Psychol Rev 2001;108(3):550-592. [doi: 10.1037//0033-295x.108.3.550]

170. Daw ND, Niv Y, Dayan P. Uncertainty-based competition between prefrontal and dorsolateral striatal systems for behavioral control. Nat Neurosci 2005 Dec 6;8(12):1704-1711. [doi: 10.1038/nn1560] [Medline: 16286932]

171. Keramati M, Dezfouli A, Piray P. Speed/accuracy trade-off between the habitual and the goal-directed processes. PLoS Comput Biol 2011 May;7(5):- [FREE Full text] [doi: 10.1371/journal.pcbi.1002055] [Medline: 21637741]

172. Nilsen WJ, Pavel M. Moving behavioral theories into the 21st century: technological advancements for improving quality of life. IEEE Pulse 2013 Sep;4(5):25-28. [doi: 10.1109/MPUL.2013.2271682] [Medline: 24056790]

173. Spruijt-Metz D, Hekler E, Saranummi N, Intille S, Korhonen I, Nilsen W, et al. Building new computational models to support health behavior change and maintenance: new opportunities in behavioral research. Transl Behav Med 2015 Sep;5(3):335-346 [FREE Full text] [doi: 10.1007/s13142-015-0324-1] [Medline: 26327939]

174. Zhang C, van Wissen A, Lakens D, Vanschoren J, De RB, IJsselsteijn W. Anticipating habit formation: a psychological computing approach to behavior change support. In: Proceedings of the 2016 ACM International Joint Conference on Pervasive and Ubiquitous Computing: Adjunct. 2016 Presented at: UbiComp '16: Proceedings of the 2016 ACM International Joint Conference on Pervasive and Ubiquitous Computing: Adjunct; September 201; Heidelberg Germany p. 1247-1254. [doi: $\underline{10.1145 / 2968219.2968439}$ ]

175. IJsselsteijn WA. Psychology 2.0 : towards a new science of mind and technology. Eindhoven, NL: Technische Universiteit Eindhoven; 2013.

176. Miller G. The smartphone psychology manifesto. Perspect Psychol Sci 2012 May 16;7(3):221-237. [doi: 10.1177/1745691612441215] [Medline: 26168460]
Abbreviations
BCT: behavior change technique
COMBI: computerized behavior intervention
JITAI: just-in-time adaptive intervention
SCT: Social Cognitive Theory
TPB: Theory of Planned Behavior
TTM: Transtheoretical Model 
Edited by $G$ Eysenbach; submitted 19.11.19; peer-reviewed by $R$ Crutzen, $S$ Sittig; comments to author 18.05.20; revised version received 26.09.20; accepted 17.02.21; published 09.04.21

Please cite as:

Zhang C, Lakens D, IJsselsteijn WA

Theory Integration for Lifestyle Behavior Change in the Digital Age: An Adaptive Decision-Making Framework

$J$ Med Internet Res 2021;23(4):e17127

URL: https://www.jmir.org/2021/4/e17127

doi: $10.2196 / 17127$

PMID: $\underline{3835036}$

(C)hao Zhang, Daniël Lakens, Wijnand A IJsselsteijn. Originally published in the Journal of Medical Internet Research (http://www.jmir.org), 09.04.2021. This is an open-access article distributed under the terms of the Creative Commons Attribution License (https://creativecommons.org/licenses/by/4.0/), which permits unrestricted use, distribution, and reproduction in any medium, provided the original work, first published in the Journal of Medical Internet Research, is properly cited. The complete bibliographic information, a link to the original publication on http://www.jmir.org/, as well as this copyright and license information must be included. 